\title{
Inhibition of Early Growth Response 1 in the Hippocampus Alleviates Neuropathology and Improves Cognition in an Alzheimer Model with Plaques and Tangles
}

\author{
Xike Qin, ${ }^{*}$ Yunling Wang, ${ }^{*}$ and Hemant K. Paudel ${ }^{* \dagger}$
}

From the Lady Davis Institute for Medical Research, ${ }^{*}$ Jewish General Hospital, Montreal, Quebec; and the Department of Neurology and Neurosurgery, ${ }^{\dagger}$ McGill University, Montréal, Quebec, Canada

\author{
Accepted for publication \\ April 6, 2017. \\ Address correspondence to \\ Hemant K. Paudel, Ph.D., Lady \\ Davis Institute for Medical \\ Research, Jewish General Hos- \\ pital, 3755 Cote Ste Catherine, \\ Montréal, QC, Canada H3T \\ 1E2. E-mail: hemant.paudel@ \\ megill.ca.
}

\begin{abstract}
A sporadic form of Alzheimer disease (AD) and vascular dementia share many risk factors, and their pathogenic mechanisms are suggested to be related. Transcription factor early growth response 1 (Egr-1) regulates various vascular pathologies and is up-regulated in both $A D$ brains and $A D$ mouse models; however, its role in $A D$ pathogenesis is unclear. Herein, we report that silencing of Egr-1 in the hippocampus by shRNA reduces tau phosphorylation, lowers amyloid- $\beta(A \beta)$ pathology, and improves cognition in the $3 \times \mathrm{Tg}-\mathrm{AD}$ mouse model. Egr-1 silencing does not affect levels of cyclin-dependent protein kinase 5 (Cdk5), glycogen synthase kinase $3 \beta$, protein phosphatase 1 , or protein phosphatase $2 A$, but reduces p35 subunit of Cdk5. Egr-1 silencing also reduces levels of $\beta$-secretase 1 (BACE-1) and BACE-1-cleaved amyloid precursor protein (APP) metabolites (secreted APP $\beta, C 99, A \beta 40$, and $A \beta 42$ ) but has no effect on presenilin 1 and presenilin 2. In hippocampal primary neurons, Egr-1 binds to $B A C E-1$ and p35 promoters, enhances tau phosphorylation, activates $\mathrm{Cdk} 5$ and BACE-1, and accelerates amyloidogenic APP processing. Blocking Cdk5 action blocks Egr-1-induced tau phosphorylation but has no effect on BACE-1 activation and amyloidogenic APP processing. Blocking BACE-1 action, on the other hand, blocks Egr-1-induced amyloidogenic APP processing but does not affect tau phosphorylation. Egr-1 regulates tau phosphorylation and $A \beta$ synthesis in the brain by respectively controlling activities of Cdk5 and BACE-1, suggesting that Egr-1 is a potential therapeutic candidate for the treatment of AD. (Am J Pathol 2017, 187: 1828-1847; http://dx.doi.org/10.1016/j.ajpath.2017.04.018)
\end{abstract}

Alzheimer disease (AD) is the major cause of dementia in humans. Progressive depositions of senile plaques and neurofibrillary tangles are the neuropathological features of AD. ${ }^{1}$ Plaques are composed mainly of amyloid- $\beta$ (A $\left.\beta\right)$ peptide derived from amyloid precursor protein (APP). APP is cleaved by $\beta$-secretase 1 (BACE-1) to generate a 99-amino acid membrane-bound protein C99 and soluble sAPP $\beta$. C99 is further cleaved by $\gamma$-secretase to produce the $\mathrm{A} \beta$ peptides. The BACE- 1 cleavage of APP initiates and is the rate-limiting step in $\mathrm{A} \beta$ production. Genetic and biochemical studies have implicated accumulation of $\mathrm{A} \beta$ in the brain as central to AD pathogenesis. ${ }^{2}$ It has been suggested that accumulation of $A \beta$ triggers toxic events leading to neurodegeneration and perhaps dementia in AD patients.
Inhibition of $\mathrm{A} \beta$ production by targeting $\mathrm{BACE}-1$ or $\gamma$-secretase has been one of the major strategies in the development of therapy against AD. ${ }^{3}$ However, BACE-1 has a relatively large active site. ${ }^{4}$ Hence, development of BACE-1 inhibitors that are permeable to the blood-brain barrier and neural membrane has been difficult. ${ }^{5}$ In addition, a direct pharmacological inhibition of BACE-1 impairs synaptic plasticity and cognitive functions in the AD mouse model owing to the involvement of BACE-1 in synaptic physiology. 6,7 The $\gamma$-secretase, on the other hand, is

Supported by a Canadian Institute for Health Research grant and an Alzheimer's Society of Canada grant.

Disclosures: None declared. 
involved in Notch signaling, which is essential for development and differentiation. ${ }^{8}$ Inhibition of $\gamma$-secretase, therefore, is associated with potential severe adverse effects. ${ }^{9}$ Moreover, pharmacological inhibitors of $\gamma$-secretase that block APP cleavage without any adverse effects on Notch reduced cerebrospinal fluid and plasma levels of $A \beta$ in healthy individuals, ${ }^{10}$ but failed to show any clinical effect in mild to moderate AD patients in phase II clinical trials. ${ }^{11}$

Neurofibrillary tangles are formed by the aggregation of hyperphosphorylated tau protein. In normal brain, tau binds and stabilizes the microtubule cytoskeleton. In AD brain, tau hyperphosphorylation is implicated to cause tau aggregation, microtubule instability, loss of axonal transport, and perhaps neurodegeneration. ${ }^{12}$ Tau hyperphosphorylation is regarded as one of the most critical pathogenic stages of AD. ${ }^{13}$ Tau-based research has focused primarily on compounds that inhibit tau kinases or reduce tau aggregation. Cyclin-dependent protein kinase $5(\mathrm{Cdk} 5)$ and glycogen synthase kinase $3 \beta$ (GSK3 $\beta$ ) are among the major brain tau kinases. ${ }^{14}$ Cdk5 knockout mice die perinatally, ${ }^{15,16}$ and a number of GSK3 $\beta$ inhibitors have failed to show any efficacy in clinical trials. ${ }^{17-19}$ Thus, despite substantial efforts in drug development and increased understanding of the pathology, currently no disease-modifying treatment is available for $\mathrm{AD}$.

Understanding the mechanism of the disease is the basis for the development of effective therapies. Although mutations that cause the rare familial form of $\mathrm{AD}$ have been identified, ${ }^{2}$ the etiology of the sporadic form, which represents approximately $95 \%$ of all $\mathrm{AD}$ cases, is unknown. However, old age, arthrosclerosis, hypertension, hyperlipidemia, and the E4 allele of the apolipoprotein E gene are some of the major risk factors for sporadic AD. These are also risk factors for vascular dementia. ${ }^{20,21}$ Pathological studies have revealed the presence of ischemic lesions in patients with $\mathrm{AD}$, and among nondemented individuals, those with coronary heart disease had greater plaque burden in the brain than those without heart disease. ${ }^{22}$ Hypoxia and ischemia resulting from vascular insufficiency promote cleavage of APP and increase A $\beta$ level in human, mouse, and rat brain. ${ }^{23}$ Likewise, focal cerebral ischemia promotes tau phosphorylation in mice, ${ }^{24}$ and hypertension increases neurofibrillary tangles in the hippocampus of nondemented elderly individuals. ${ }^{25}$ Although increasing numbers of epidemiological, neuroimaging, pathological, pharamacotherapeutics, and clinical studies suggest that pathogenic mechanisms of vascular dementia and $\mathrm{AD}$ are somehow related, ${ }^{20,21}$ the molecular link between the two pathologies is yet to be found.

Early growth response 1 (Egr-1) is a zinc finger transcription factor that regulates a number of cell functions, including cell proliferation, apoptosis, cell growth, and signal transduction. ${ }^{26,27}$ In the central nervous system, Egr-1 is induced during ischemic stroke, hypoxia, brain injury, and inflammation and plays an important role in the induction and maintenance of various vascular pathologies. ${ }^{26-29}$ A recent study analyzed a microarray data set of 31 samples corresponding to hippocampal gene expression from $22 \mathrm{AD}$ subjects of varying degree of severity and 9 controls. ${ }^{30}$ Using modern bioinformatics methods, this study uncovered 1372 probe gene expression signatures that represented a high degree of consensus with established pathological markers of $\mathrm{AD}$ progression. More important, the authors found that Egr-1 is significantly up-regulated in $\mathrm{AD}$ brain, correlating with progression of the disease. ${ }^{30}$ Consistent with this report, a number of subsequent studies have reported up-regulation of Egr-1 in human AD brains. $^{31-34}$ Recently, Egr-1 level was reported to be elevated in the brains of APP, ${ }^{31}$ APP/presenilin 1 (PS1), ${ }^{35}$ and $3 \times \mathrm{Tg}-\mathrm{AD}^{36}$ mouse models of $\mathrm{AD}$. In addition, genetic deletion of Egr-1 reduces tau phosphorylation in mouse brain, and overexpression of Egr-1 promotes tau phosphorylation in rat primary neurons in culture and in rat hippocampus. ${ }^{32}$ The pathological significance of these observations is unclear.

Transgenic mice expressing mutated human APP or mutated both APP and PS1 are often used animal models for $\mathrm{AD}$ research. Unlike $\mathrm{AD}$ patients, these mice do not display neurofibrillary tangles. ${ }^{1}$ 3xTg-AD mice develop agedependent plaques, tangles, and cognitive decline, recapitulating many salient feature of $\mathrm{AD} .{ }^{37}$ Therefore, to determine the role of Egr-1 in AD pathogenesis, we have administered lentivirus-expressing shRNA against Egr-1 into the hippocampus of 10-month-old 3xTg-AD mice. We show that targeted knockdown of Egr-1 in the hippocampus inhibits activities of Cdk5 and BACE-1, alleviates levels of both phosphorylated tau and $A \beta$, and improves cognition in this AD mouse model. Our data suggest that Egr-1 is a potential therapeutic target for the treatment of AD.

\section{Materials and Methods}

\section{Animals}

All experiments involving animals were performed according to the guidelines of Canadian Council of Animal Cares and Lady Davis Institute for Medical Research (Montréal, QC, Canada). Both 3xTg-AD and nontransgenic (nTg) mice in hybrid C57BL6/129 background were gifts from Dr. Hyman Schipper (Lady Davis Institute for Medical Research). 3xTg-AD mice express human APP with Swedish mutation (KM 670/671NL), human tau with P301L mutation, and human PS1M146V. ${ }^{37}$ All mice were genotyped by PCR.

\section{Antibodies and Chemicals}

Polyclonal antibodies against green fluorescent protein (GFP), Egr-1, Myc, PP1, Thr ${ }^{320}$-phosphorylated PP1, PP2A, Tyr-phosphorylated PP2A, tau, and site-specific phosphorylated tau were described previously. ${ }^{32}$ Antineprilysin, 
anti-insulin-degrading enzyme, anti-PS1, anti-presenilin 2 (PS2) were obtained from Millipore (Oakville, ON, Canada). Monoclonal antibodies against Tyr-tubulin and Actubulin were described previously. ${ }^{38}$ Human and mouse anti-APP-C-terminal and anti-sAPP $\beta$ were from Millipore. Roscovitine was obtained from Sigma-Aldrich (Oakville, ON, Canada).

\section{Lentiviral Vector and Intracerebral Injection}

Detail of construction of lentiviral vector expressing siRNA against mouse Egr-1 is described previously. ${ }^{39}$ Briefly, four unique siRNA cassettes were obtained through GeneCopoeia (MSH032227; Rockville, MD). Each of these constructs, in a lentivirus GFP vector, expressed a 19 mer, either a noneffective scrambled control (shRNA-Ctl) sequence (5'CAAAGCCAAGCAAACCAAT- $3^{\prime}$ ) or one of the three Egr1 targeting sequences (Sh-1, 5'-CGCTCTGAATAATGAGAAG- $3^{\prime}$; Sh-2, 5'-ACTGGTCTTTCAGACATGA-3'; or Sh-3, 5'-AGCGCTAGACCATCAAGTT- $3^{\prime}$ ) driven by histone $\mathrm{H} 1$ promoter. These shRNAs were validated by transfection into the mouse cell line, 3T3L1, followed by Western blot analysis for Egr-1 expression. Although all three shRNAs reduced endogenous Egr-1 by $>50 \%$, shRNA-Ctl had no effect. Sh3 was most effective and down-regulated Egr-1 expression by $82 \%$ in $3 \mathrm{~T} 3 \mathrm{~L} 1$ cells and $85 \%$ in mouse hippocampal primary neurons in culture ${ }^{39}$ and was selected for in vivo experiments. Lentiviruses expressing shRNA-Egr-1 and shRNA-Ctl were produced as per manufacturer's protocol. Briefly, the DNA was transfected along with a LentiX HTX Packaging Mix (Clontech, Mountain View, CA) into the Lenti-X 293T cells. The virus was purified from the supernatant 48 and 72 hours after transfection. ${ }^{32,39}$ The titer of purified virus was determined by flow cytometry, and the virus was stored frozen at $-80^{\circ} \mathrm{C}$.

A total of $203 \times \mathrm{Tg}-\mathrm{AD}$ and $20 \mathrm{nTg}$ received viral injection. For each group, a total of 10 mice received shRNA-Ctl and the other 10 received shRNA-Egr-1. One 3xTg-AD mouse receiving shRNA-Egr-1 died after 2 weeks. Viral injection was performed as described previously. ${ }^{32}$ Briefly, 3xTg-AD and $\mathrm{nTg}$ control mice (10 months old each) were anesthetized with isoflurane and placed into a Kopf stereotaxic apparatus, where they received bilateral injections for the lentiviral preparations $\left(1.8 \times 10^{9}\right.$ multiplicity of infection) into the hippocampus (coordinates, from bregma: medial/lateral, 1.94; anterior/posterior, $1.25 ; \mathrm{dorsal} / \mathrm{ventral}, 1.50)$. Injections were delivered via a $5 \mu \mathrm{L}$ Hamilton microsyringe connected to a PhD Ultra Pump Syringe (Harvard Apparatus, Saint-Laurent, QC, Canada) with a 27 gauge needle. Injection ( $2 \mu \mathrm{L}$ per side) was delivered at a rate of $0.25 \mu \mathrm{L} /$ minute. The needle was left for an additional $5 \mathrm{mi}-$ nutes after the injection to allow diffusion of virus into the tissue.

\section{Morris Water Maze Testing}

After 4 months of viral injection, mice were tested for spatial learning/memory performance in the Morris water maze by an observer blind to the experiment and the genotype of mice, as described. ${ }^{40}$ The maze consisted of a circular pool (1.2 m in diameter) filled to a depth of $55 \mathrm{~cm}$ with water rendered opaque by addition of white gouache, and maintained at $23^{\circ} \mathrm{C}$ to $24^{\circ} \mathrm{C}$. A square plexiglass platform $(10 \times 10 \mathrm{~cm}), 0.5 \mathrm{~cm}$ below water level, was left in the same location (southwest quadrant, approximately $0.5 \mathrm{~m}$ in from the side) for the duration of each experiment. Latency, distance, and swimming path to find the platform were recorded with a video camera connected to a computerized tracking system (HVS Image, Buckinham, UK). Each mouse was given a block of four trials/day for 5 consecutive days. Three cardinal points (northeast, northwest, and southeast) were used as release points, with the restriction that no one release point was used more than twice in 1 day. Mice were placed in the pool and allowed to swim for a maximal time of 60 seconds. If a mouse did not find the platform within this time, it was placed on it for 15 seconds. The intertrial intervals ranged between 10 and 15 minutes.

Four hours after the last training trial on day 5, mice were given a probe trial (60 seconds) with the platform removed. Latency and distance traveled in each quadrant were measured. The quadrant in which the platform was previously located (southwest) was designated as the target quadrant. During the probe trial, latencies to former location of the platform were measured and the number of times the mouse crossed the former platform location was recorded.

\section{Immunohistochemistry}

After behavior tests, mice were subjected to neuoropathological examinations. Mice were anesthetized and transcardially perfused with cold phosphate-buffered saline. The right hemibrain was post-fixed in $4 \%$ paraformaldehyde $\left(\mathrm{pH} \mathrm{7.4)}\right.$ at $4{ }^{\circ} \mathrm{C}$ for 48 hours and divided into sections on a vibratome. Coronal sections $(50 \mu \mathrm{m}$ thick) corresponding to the hippocampus and cortex were used for histology. The right hemisphere was dissected into hippopcampal and cortical samples and either frozen at $-80^{\circ} \mathrm{C}$ or used freshly for measurement of proteins. The procedure for immunohistochemistry using immunostainer Discovery XT from Ventana (Tucson, AZ) and quantification of images was described previously. ${ }^{39}$ Briefly, sections were labeled with mouse anti-Egr-1 or rabbit anti-GFP (1:100; Cell Signaling, Danvers, MA), followed by Alexa-red or fluorescein isothiocyanate-blue conjugated secondary antibodies. For plaque detection, sections were labeled with rabbit anti-human A $\beta 42$ (1:200; Cell Signaling), followed by Alexa Fluoro conjugated secondary antibody. For quantification, slides were scanned at $\times 400$ magnification [resolution of $0.25 \mu \mathrm{m} /$ pixel (100,000 pixels/inch)] using an Aperio ScanScope AT Turbo (Leica Biosystems, Wetziar, Germany). The background illumination levels were calibrated using a prescan procedure. Acquired digital images representing whole 
tissue sections were analyzed applying the Spectrum Analysis algorithm package and ImageScope analysis software version 11.2 (Aperio Technologies, Wetziar, Germany). A rectangular region of interest, $25 \mu \mathrm{m}^{2}$ in size, was defined. The immunoreactivity value for each region of interest was obtained. The immunoreactivity within each region of interest in every section was averaged to generate a mean immunoreactive value for each animal. Data were averaged from six mice in each group, with four regions $(n=24)$ for each genotype, and are expressed as the fold of nTg.

\section{Construction of Mouse shRNA against BACE-1, Lentiviral Production, Cell Culture, and Viral Infection}

shRNA against mouse $B A C E-1$ was constructed as described previously. ${ }^{39}$ Briefly, 19 mer either BACE-1 targeting sequence siBACE-1 (5'-GTTCGCTGTCTCACAGTCA$\left.3^{\prime}\right)^{41}$ or noneffective scrambled control siCtl $\left(5^{\prime}\right.$-CAAAGCCAAGCAAACCAAT-3') was subcloned into lentiviral vector pLVX-IRWS-ZsGreen1 (Clontech) at the EcoRI/XbaI site. Lentivirus was produced as described previously. ${ }^{39}$ DNA was transfected along with a Lenti-X HTX Packaging Mix into the Lenti-X 293T cells, and the virus was harvested after 48 and 72 hours from the supernatant and purified. The titer of purified virus was determined by flow cytometry, and the virus was stored at $-80^{\circ} \mathrm{C}$. To validate the shRNA construct, lentivirus was infected into mouse hippocampal primary neurons. After 48 hours of infection, neurons were analyzed by Western blot analysis. Construction and production of lentivirus expressing human Egr-1 with a Myc tag at the C terminus was described previously. ${ }^{39}$ Hippocampal neurons were prepared from $\mathrm{P} 0$ new born rat or mouse pups (Charles River, Senneville, QC, Canada), as described previously. ${ }^{39}$ Neurons 2 weeks in culture were infected with Ln-vector or Ln-Egr-1 (multiplicity of infection of 20 each). After 72 hours, neurons were either analyzed by immunocytochemistry or homogenized in extraction buffer for Western blot analysis.

\section{Immunocytochemistry, Image Acquisition, and Quantification}

Immunocytochemistry was performed as described previously. ${ }^{39}$ Briefly, Ln-Egr-1- or Ln-vector-infected neurons were fixed and labeled with rabbit anti-BACE-1 (1:200; Cell Signaling), rabbit anti-Myc (1:200; Cell Signaling), or GFP (mouse, 1:1000; Cell Signaling), followed by Alexa Fluor 532 or 488 goat anti-rabbit or goat anti-mouse secondary antibody. Labeled neurons were viewed by using the LSM Pascal (Zeiss, Oberkochen, Germany) confocal microscopy system. At least 15 labeled neurons were randomly chosen from each group for quantification from three to four coverslips. Immunointensity was analyzed along 30 to $40 \mu \mathrm{m}$ of dendritic length of each neuron by Volocity image analysis software version 6.3 (Improvision,
Coventry, England). Data were averaged from four independent cultures.

\section{BACE-1 Activity Assay, Sandwich Enzyme-Linked Immunosorbent Assay, and Western Blotting for $A \beta 40$ and $A \beta 42$}

BACE-1 activity was measured by using the $\beta$-Secretase fluorogenic activity assay kit (catalog number 565785; Calbiochem, Oakville, ON, Canada), following the manufacturer's instruction manual. Briefly, cells were homogenized in the extraction buffer and centrifuged, and the supernatant (50 $\mu \mathrm{L}$ each) was transferred to a fluorescence plate reader. $\beta$-Secretase substrate was added to each well, and the plate was incubated for 1 hour at $37^{\circ} \mathrm{C}$ in the dark. After incubation, fluorescence was measured with excitation at 335 to $355 \mathrm{~nm}$ and emission at 495 to $570 \mathrm{~nm}$. Background reading from buffer and the substrate was subtracted. A $\beta 42$ in the cell culture medium was measured using mouse A $\beta 42$ ELISA Kit (Invitrogen, Carlsbad, CA), following the instruction manual. Culture medium $(50 \mu \mathrm{L})$ was pipetted into the enzyme-linked immunosorbent assay plate well coated with mouse antibody specific to the $\mathrm{N}$ terminal of $A \beta 42$. After incubation and washing, rabbit polyclonal antibody specific to $\mathrm{A} \beta 42 \mathrm{C}$ terminal was added. Bound antibody was detected by using horseradish peroxidase-labeled secondary antibody and an enzyme-linked immunosorbent assay plate reader at $\mathrm{OD}_{450} \mathrm{~nm}$. For Western blotting, samples were separated on $10 \%$ to $20 \%$ Tricine gel (Invitrogen) and probed against either mouse or human anti-A $\beta 40$ or anti-A $\beta 42$ antibody.

\section{RNA Extraction and $q P C R$}

Total RNA was purified using RNeasy minikits (Qiagen, Montreal, QC, Canada) from hippocampal primary neurons using the manufacturer's instruction manual and as described previously. ${ }^{39}$ Total RNA $(1 \mu \mathrm{g})$ was used for the first-strand synthesis with Super Script Reverse Transcriptase II and oligo (dT) or random primer (Invitrogen). Realtime quantitative PCR (qPCR) was performed using an SYBR Green PCR kit (Qiagen) with gene-specific primers (Table 1) using a 7500 real-time PCR system (Applied Biosystems, Foster City, CA). Data were analyzed by qPCR software 7500 version 2.0.4 (Applied Biosystems). The relative concentrations of the genes of interest were determined using the comparative threshold cycle $\left(\Delta C_{T}\right)$ method after normalization to the endogenous control (glyceraldehyde-3-phosphate dehydrogenase). ${ }^{39}$

\section{Chromatin Immunoprecipitation Assay}

Hippocampal primary neurons infected with Ln-vector or Ln-Egr-1 for 48 hours were subjected to chromatin immunoprecipitation assay using Magna ChIP T/MA/G Millipore Kit (Millipore), following the manufacturer's instructions 
Table 1 Primer List

\begin{tabular}{|c|c|}
\hline Genes & Primers \\
\hline \multicolumn{2}{|l|}{ qPCR } \\
\hline \multirow[t]{2}{*}{ Rat $B A C E-1$} & Forward: 5'-CСTCCGAAAGTCTGTGTATGTG-3' \\
\hline & Reverse: $5^{\prime}$-CAGTTGGAACCATTGATGAAGA-3' \\
\hline \multirow[t]{2}{*}{ Rat $p 35$} & Forward: 5'-GAAATCTCCTACCCGCTCAA-3' \\
\hline & Reverse: 5'-GTCCCAAAAGGCTTCCTTG-3' \\
\hline \multirow[t]{2}{*}{ Rat GAPDH } & Forward: 5'-CGCCTGCTCTCCTGTT-3' \\
\hline & Reverse: 5'-CCATGGTGTCTGAGCGATGT-3' \\
\hline \multicolumn{2}{|l|}{ ChIP assay } \\
\hline \multirow[t]{2}{*}{ Rat $B A C E-1$} & Forward: 5'-AGAGGGCATCCCAGACCCCTTTC-3' \\
\hline & Reverse: 5'-AAAGCCAAAGGGTTTTTGCTTTGGG-3' \\
\hline \multirow[t]{2}{*}{ Rat $p 35$} & Forward: 5'-CGCGCGTTCCCGCCGCCCGCGCCG-3' \\
\hline & Reverse: 5'-AGCCCGCCGGCTCCGCCCCCGCCCCG-3' \\
\hline \multirow[t]{2}{*}{ Rat GAPDH } & Forward: $5^{\prime}-$ GACATGCCGCCTGGAGAAAC- $3^{\prime}$ \\
\hline & Reverse: 5'-AGCCCAGGATGCCCTTTAGT-3' \\
\hline
\end{tabular}

ChIP, chromatin immunoprecipitation; qPCR, real-time quantitative PCR.

and as described previously. ${ }^{39}$ Neurons were cross-linked, and the DNA was fragmented to 200 to $1000 \mathrm{bp}$ in length. Chromatin solution $(100 \mu \mathrm{L})$ was immunoprecipitated using $5 \mu \mathrm{g}$ of either monoclonal anti-Egr-1 (MABC 1023; Millipore) or IgG control. Input and immunoprecipitated samples were digested with proteinase $\mathrm{K}$ to reverse the cross-linking. The DNA was purified and analyzed by qPCR using primers flanking $B A C E-1,{ }^{42} P 35,{ }^{43}$ or $G A P D H$ (control) promoter (Table 1).

\section{Kinase Assay}

Activities of GSK3 $\beta$ and Cdk5 were assayed as described previously. ${ }^{32}$ To prepare GSK3 $\beta$ substrate, a synthetic peptide derived from cAMP response element-binding protein (KRREILSRRPSYR) was first phosphorylated by protein kinase $\mathrm{A}$, and then the phosphorylated peptide was purified by high-performance liquid chromatography. Cdk5 substrate was KTPKKAKKPKTPKKAKKL peptide. Kinase activity assays were performed using any of the above peptides as the substrate. The final concentrations of the various assay components were $50 \mathrm{mmol} / \mathrm{L}$ Tris- $\mathrm{HCl}(\mathrm{pH}$ 7.4), $1 \mathrm{mmol} / \mathrm{L}$ EDTA, $0.1 \mathrm{mmol} / \mathrm{L}$ EGTA, $10 \mathrm{mmol} / \mathrm{L}$ $\mathrm{MgCl}_{2}, 0.5 \mathrm{mmol} / \mathrm{L} \gamma^{32} \mathrm{P}$-ATP, $20 \mu \mathrm{mol} / \mathrm{L}$ of substrate peptide, and carryover components of cell extract. The reaction was initiated by the addition of $10 \mu \mathrm{L}$ of cell extract to $90 \mu \mathrm{L}$ of mixture containing the rest of the assay components. After 1 hour at $30^{\circ} \mathrm{C}$, aliquots were removed and analyzed by filter paper assay.

\section{Statistical Analysis}

All data were analyzed by one-way analysis of variance, followed by Newman-Keuls post hoc test for multigroup comparisons and $t$-test for comparisons between two groups. For water maze data, latencies and the distances swam across the two trials for each mouse every day were averaged. These means were analyzed across the 5 days for testing. A one-way repeated measurement of analysis of variance was used for main effect (ie, group or treatment comparison) with day as the repeated measure and latency or distance swam as the dependent variable. The NewmanKeuls test was used for post hoc analysis. For probe trials, the means were compared between groups by one-way analysis of variance, followed by Newman-Keuls post hoc test. All data are presented as means \pm SEM, and differences with $P<0.05$ were considered significant.

\section{Results}

\section{Inhibition of Egr-1 in the Hippocampus Alleviates Spatial Learning Deficits in 3xTg-AD Mice}

We obtained four unique siRNA cassettes from GeneCopoeia each in a lentivirus GFP vector, expressing either a noneffective scrambled control (shRNA-Ctl) or one of the three Egr-1 targeting sequences driven by histone $\mathrm{H} 1$ promoter. We chose the most effective shRNA-Egr-1 that reduced endogenous Egr-1 expression by $82 \%$ in $3 \mathrm{~T} 3 \mathrm{~L} 1$ cells and $85 \%$ in mouse hippocampal primary neurons in culture. ${ }^{39}$ To confirm the specificity of the shRNA and to exclude the possibility of off-targeting effect, we obtained a rescued Egr1 knockdown phenotype caused by shRNA-Egr-1 in mouse hippocampal primary neurons by overexpressing Egr-1. shRNA-Egr- 1 causes accumulation of $\alpha$-amino-3-hydroxy5-methyl-4-isoxazole propionic acid receptor Glu-2 receptor on the surface of neurons. This effect was almost completely rescued by Ln-Egr-1 but not by Ln-vector. ${ }^{39}$

We next bilaterally injected lentivirus expressing shRNAEgr-1 or non-specific shRNA-Ctl into the hippocampus of 10-month-old 3xTg-AD and age-matched nTg mice. After 4 months, mice were analyzed for behavior, followed by neuropathology. To determine the effects of Egr-1 inhibition on the behavior, we analyzed mice for hippocampaldependent spatial memory by the Morris water maze test. One-way analysis of variance, followed by Newman-Keuls post hoc test of data, determined that the swimming speed, percentage of total time floating, percentage of thigmotaxis time, and percentage of thigmotaxis path of $3 \times \mathrm{Tg}-\mathrm{AD}$ and nTg mice receiving shRNA-Ctl or shRNA-Egr-1 were not significantly different (Figure 1A). These data suggested that compared to $\mathrm{nTg}, 3 \mathrm{xTg}-\mathrm{AD}$ mice do not display any motor defect, anxiety, fear, or depression; and shRNA-Egr-1 or shRNA-Ctl delivery into the hippocampus does not cause any of these symptoms in any of these animals. ${ }^{40}$ In contrast, compared to nTg mice receiving shRNA-Ctl (nTg-shRNA$\mathrm{Ctl}$ ), 3xTg-AD mice receiving shRNA-Ctl (3xTg-ADshRNA-Ctl) displayed significantly longer escape latency during the training (Figure 1B), spent less time in the target quadrant and target swimming path (Figure 2A), and had fewer target platform crossings during the probe trial (Figure 2B). These observations are as expected and indicated that $3 \times \mathrm{Tg}-\mathrm{AD}$ mice are cognitively deficient.

3xTg-AD mice receiving shRNA-Egr-1 (3xTg-ADshRNA-Egr-1) reached the platform faster than 3xTg-ADshRNA-Ctl on each day 3 to 5 of the trial (Figure 1B). On 
A

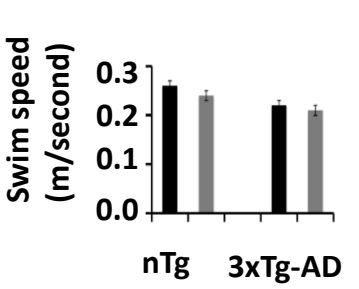

ShRNA-CtI

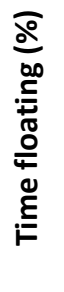

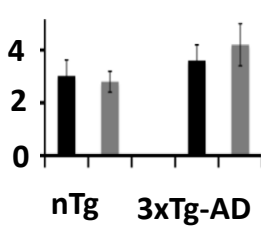
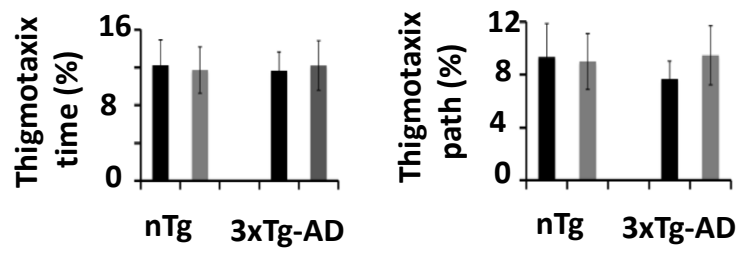

B
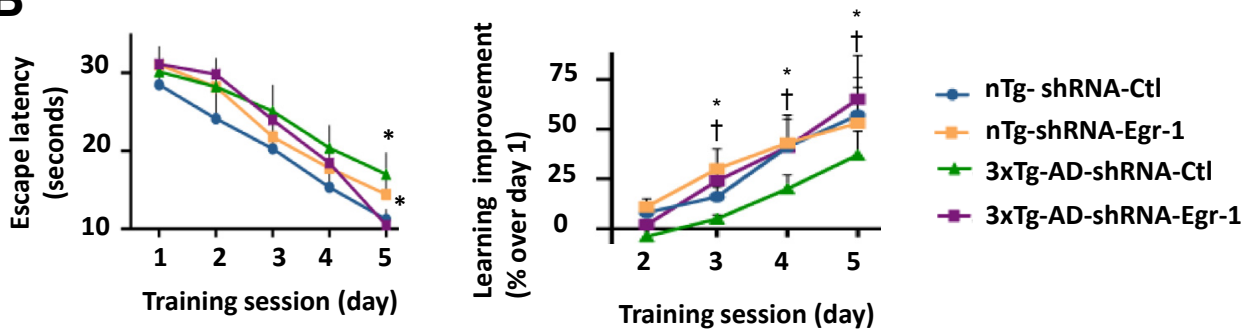

Figure 1 Inhibition of Egr-1 in the hippocampus improves learning deficits in 3xTg-AD mice. Lentivirus expressing shRNA-Egr-1 or shRNA-Ctl was injected into the hippocampus of $3 \times \mathrm{Tg}-\mathrm{AD}$ and age-matched $\mathrm{nTg}$ controls. After 4 months of injection, mice were tested for learning and memory on the water maze. A: shRNA-Egr-1 delivery into the hippocampus does not cause motor defect, anxiety, or depression in mice. During the probe trial on day 5, 3xTg-AD injected with shRNA-Ctl (3xTg-AD-Ctl), 3xTg-AD injected with shRNA-Egr-1 (3xTg-AD-Egr-1), nTg mice injected with shRNA-Ctl (nTg-shRNA-Ctl), and nTg injected with shRNA-Egr-1 (nTg-shRNA-Egr-1) were tested for swim speed, percentage of total time floating (swim speed $<0.05 \mathrm{~m} /$ second), a sign of anxiety and/or depression, thigmotaxis time (percentage of total time spent within $5 \mathrm{~cm}$ of the pool wall, a measure of anxiety or fear), and thigmotaxis path (percentage of swim path spent within $5 \mathrm{~cm}$ of the pool wall, a measure of anxiety or fear). No statistical differences were observed among groups in all of the above parameters $(P>0.05$, one-way analysis of variance and Newman-Keuls post hoc analysis). B: Escape latency and learning improvement during platform trial. Left panel: $3 \times T g-A D$-shRNA-Ctl mice were inferior to nTg-shRNA-Ctl, showing longer escape latency. However, 3xTg-AD-shRNA-Egr-1 mice displayed significantly shorter escape latency than 3xTg-AD-shRNA-Ctl on day 5. Right panel: Learning improvement. Learning improvement of a mouse is the reduction in escape latency time in each day of training with respect to day 1 training. All groups of mice displayed progressive improvement in learning with increase in the day of training. Compared to nTg-shRNA-Ctl (blue), 3xTg-AD-shRNA-Ctl mice were significantly slow in learning on day 3, day 4, and day 5. However, 3xTg-AD-shRNA-Egr-1 mice make significantly more progress on day 3, day 4, and day 5 versus 3xTg-AD-shRNA-Ctl mice. Data expressed as means \pm SEM. $n=10 \mathrm{nTg}$-shRNA-Ctl, nTg-shRNA-Egr-1, and 3xTg-AD-shRNA-Ctl (A and $\mathbf{B}) ; n=9$ 3xTg-AD-shRNA-Egr-1 (A and B). * $P<0.053 \times$ Tg-AD-shRNA-Ctl mice versus $n T$ T-shRNA-Ctl mice (repeated measures of one-way analysis of variance and Newman-Keuls post hoc analysis); ${ }^{\dagger} P<0.053 \times$ Tg-AD-shRNA-Egr-1 mice versus 3xTg-AD-shRNA-Ctl mice (repeated measures of one-way analysis of variance and Newman-Keuls post hoc analysis).

the fifth day, 3xTg-AD-shRNA-Egr-1 mice reached the platform $38.5 \%$ faster than $3 \times$ Tg-AD-shRNA-Ctl mice (Figure 1B). Furthermore, on days 3, 4, and 5, although 3xTg-AD-shRNA-Ctl mice reached the platform 5\%, $20 \%$, and $37.3 \%$ faster, respectively, than on day 1 , 3xTg-AD-shRNA-Egr-1 mice reached the target platform $24.3 \%, 41.7 \%$, and $65.3 \%$ faster, respectively, than on day 1 (Figure 1B). These data showed that compared to $3 \times \mathrm{Tg}$ AD-shRNA-Ctl mice, 3xTg-AD-shRNA-Egr-1 mice were $19.5 \%, 21.3 \%$, and $28.0 \%$ better learners on days 3,4 , and 5 , respectively.

\section{Inhibition of Egr-1 in the Hippocampus Improves Memory Deficits in 3xTg-AD Mice}

On day 5, mice were subjected to the probe trial for memory. Both nTg-shRNA-Ctl and nTg-shRNA-Egr-1 mice displayed similar preference of various quadrants and spent significantly more time in target than any of the other quadrants (Figure 2A). 3xTg-AD-shRNA-Ctl mice, on the other hand, spent $8.2 \% \pm 2.08 \%$ less $(P<0.05)$ and $7.0 \% \pm 2.59 \%$ more $(P<0.05)$ time in the target and anti-clockwise quadrants, respectively, than the nTg-shRNA-Ctl mice. In contrast,
3xTg-AD-shRNA-Egr-1 mice spent $11.61 \% \pm 2.59 \%$ more $(P<0.05)$ time in the target quadrant and $8.07 \% \pm 2.6 \%$ less $(P<0.05)$ time in the counterclockwise quadrant than $3 \times \mathrm{xT}-$ AD-shRNA-Ctl mice. 3xTg-AD-shRNA-Egr-1 mice displayed quadrant preference and time spent in the target quadrant similar to nTg-shRNA-Ctl mice.

Next, we compared percentage of total swim path spent by mice in various quadrants (Figure 2A). Again, nTg-shRNACtl and nTg-shRNA-Egr-1 mice had a similar percentage of total swim path in the various quadrants. $3 \mathrm{xTg}$-AD-shRNACtl mice, on the other hand, had significantly reduced swim path in the target quadrant than nTg-shRNA-Ctl mice. However, 3xTg-AD-shRNA-Egr-1 mice had $11.6 \% \pm 1.8 \%$ more $(P<0.05)$ than 3xTg-AD-shRNA-Ctl and similar to nTg-shRNA-Ctl swimming path in the target quadrant. Finally, although nTg-shRNA-Ctl and nTg-shRNA-Egr-1 mice had a similar number of target platform crossings, 3xTg-AD-shRNA-Ctl mice showed significantly fewer number of crossings, as expected. In contrast, 3xTg-ADshRNA-Egr-1 mice had $1.83 \pm 0.4$ times more crossings $(P<0.05)$ than 3xTg-AD-shRNA-Ctl mice. Thus, 3xTgAD-shRNA-Egr-1 mice spent significantly more time in the target quadrant, had more target swimming path, and had 

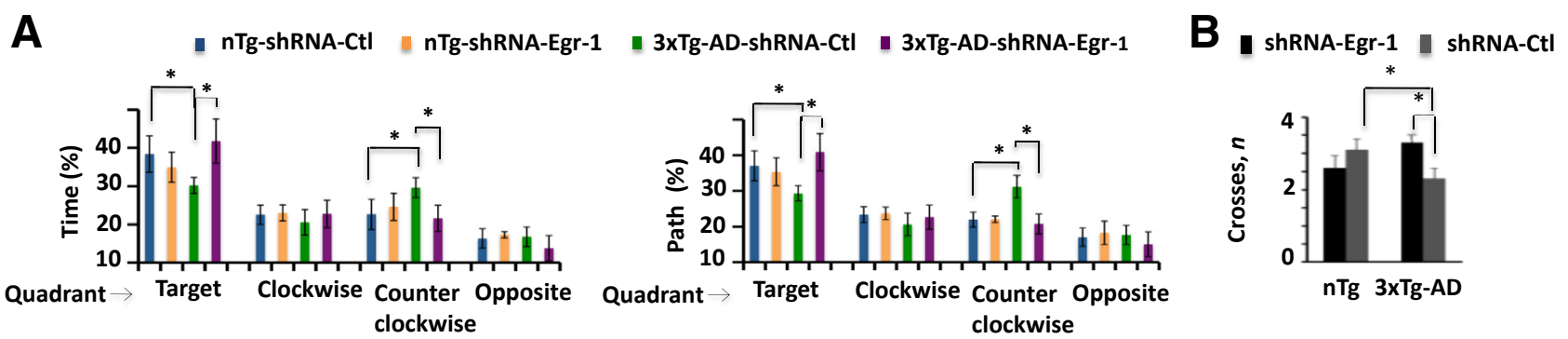

Figure 2 Inhibition of Egr-1 in the hippocampus improves memory deficits in 3xTg-AD mice. On day 5, mice were tested for memory by probe trial. Percentage time and percentage path spent in each quadrant of the pool and number of target platform crossings were recorded. A: Left panel: The average percentage of the total time spent in the indicated quadrant is shown. Compared to nTg-shRNA-Ctl, 3xTg-AD-shRNA-Ctlspent significantly less time in the target quadrant and more time in the counterclockwise quadrant (one-way analysis of variance and Newman-Keuls post hoc analysis). However, compared to 3xTg-AD-shRNA-Ctl, 3xTg-AD-shRNA-Egr-1 mice spent significantly more time in the target quadrant and less time in the counterclockwise quadrant. Right panel: Percentage path in various quadrants. Average percentage path in each quadrant is shown. 3xTg-AD-shRNA-Ctl mice have significantly less percentage target path than nTg-shRNA-Ctl. 3xTg-AD-shRNA-Egr-1, on the other hand, have significantly higher percentage target path than 3xTg-AD-shRNA-Ctl mice (one-way analysis of variance and Newman-Keuls post hoc analysis). B: Platform crossing. 3xTg-AD-shRNA-Ctl mice have significantly fewer number of platform crosses than nTg-shRNA-Ctl. 3xTg-AD-shRNA-Egr-1, on the other hand, have significantly higher number of crossings of former platform location than those 3xTg-AD-shRNA-Ctl mice and almost similar number with nTg-shRNA-Ctl controls (one-way analysis of variance and Newman-Keuls post hoc analysis). Data are expressed as average \pm SEM (A, left panel) or means \pm SEM (A, right panel, and $\mathbf{B}) . n=10 \mathrm{nTg}$-shRNA-Ctl, nTg-shRNA-Egr-1, and 3xTg-AD-shRNA-Ctl (A and $\mathbf{B}) ; n=9$ 3xTg-AD-shRNA-Egr-1 (A and $\mathbf{B}) .{ }^{*} P<0.05$ (one-way analysis of variance and Newman-Keuls post hoc analysis).

more target platform crossings than 3xTg-AD-shRNA-Ctl mice (Figure 2). The performance of 3xTg-AD-shRNAEgr-1 mice compared with nTg-shRNA-Ctl mice during the final day of the training session and on the probe trial. This result showed that shRNA-Egr-1 delivery into the hippocampus rescues cognitive defect in $3 \times \mathrm{Tg}-\mathrm{AD}$ mice.

\section{shRNA-Egr-1 Delivery Down-Regulates Egr-1 in the Hippocampus}

After the memory tests, mice were subjected to neuropathological examinations. All shRNA-Ctl and shRNA-Egr-1 receiving sites displayed GFP fluorescence (shRNA expression) at comparable levels (Figure 3, A and B). Both 3xTgAD-shRNA-Egr-1 and nTg-shRNA-Egr-1 mice showed significantly reduced Egr-1 immunostaining when compared to mice injected with shRNA-Ctl at injected sites (Figure 3B). Western blot analysis showed that compared to the nTgshRNA-Ctl, 3xTg-AD-shRNA-Ctl mice had 1.8- and 1.7fold higher levels of Egr-1 in the hippocampus and the cortex, respectively (Figure 3, C and D). These data determined that $3 \times \mathrm{Tg}-\mathrm{AD}$ mice have an elevated level of Egr-1 in the brain, as reported. ${ }^{36}$ More important, $3 x$ Tg-AD-shRNA-Egr-1 mice had an Egr-1 level 70\% less than 3xTg-AD-shRNA-Ctl mice in the hippocampus (Figure 3, C and D). Likewise, nTgshRNA-Egr-1 mice displayed an Egr-1 level reduced by $75 \%$ when compared to nTg-shRNA-Ctl mice. This effect was not seen in the cortex of both genotypes, which did not receive lentivirus injection. These results showed that shRNA-Egr-1 had specifically inhibited Egr-1 level in the hippocampus.

\section{Inhibition of Egr-1 Reduces Tau Hyperphosphorylation in the Hippocampus}

Accumulation of hyperphosphorylated tau is one of the characteristic pathological features of the $\mathrm{AD}$ brain. ${ }^{1}$ Therefore, to determine the effects of Egr-1 inhibition on neuropathology, we analyzed tau phosphorylation in the hippocampus of shRNA-treated mice (Figure 4A). Compared to nTg-shRNACtl, 3xTg-AD-shRNA-Ctl mice had significantly elevated levels of phosphorylated tau on all sites tested (Figure 4A). In addition, these mice also had 1.6-fold more total tau when compared to the nTg-shRNA-Ctl cohort. shRNA-Egr-1 silencing did not affect total tau level in both $3 \times \mathrm{Tg}-\mathrm{AD}$ and nTg littermates (Figure 4A). However, compared to 3xTg-ADshRNA-Ctl mice, tau phosphorylation at $\mathrm{Ser}^{404}, \mathrm{Ser}^{262}, \mathrm{Ser}^{235}$, $\mathrm{Thr}^{231}$, and $\mathrm{Thr}^{181}$ was significantly reduced in $3 \mathrm{xTg}-\mathrm{AD}$ shRNA-Egr-1 mice (Figure 4B). Phosphorylation at $\mathrm{Ser}^{214}$, on the other hand, was similar in the two groups (Figure 4B).

\section{Inhibition of Egr-1 Stabilizes Microtubule Cytoskeleton in the Hippocampus}

In the $\mathrm{AD}$ brain, tau phosphorylation inhibits tau binding to microtubules and causes microtubule instability. ${ }^{1,12} 3 \times \mathrm{Tg}$ AD-shRNA-Ctl mice had 2.5-fold higher levels of Tyr-tubulin, representing unstable microtubules, and 2.3-fold less Ac-tubulin, representing stable microtubules, compared to nTg-shRNA-Ctl controls (Figure 4C), indicating that microtubules in the hippocampus of $3 \times \mathrm{Tg}-\mathrm{AD}$ mice are highly unstable. In 3xTg-AD-shRNA-Egr-1 mice, the amount of Tyr-tubulin was 2.7-fold less and Ac-tubulin 2.8 -fold more than in 3xTg-AD-shRNA-Ctl mice. The total tubulin level remained similar in the two experimental groups. These data determined that Egr-1 inhibition stabilizes microtubules in the hippocampus of $3 \times \mathrm{Tg}-\mathrm{AD}$ mice.

\section{Inhibition of Egr-1 Down-Regulates the p35 Subunit of $\mathrm{Cdk} 5$}

The balance of tau phosphorylation in the brain is regulated by the activities of tau kinases and tau-specific 

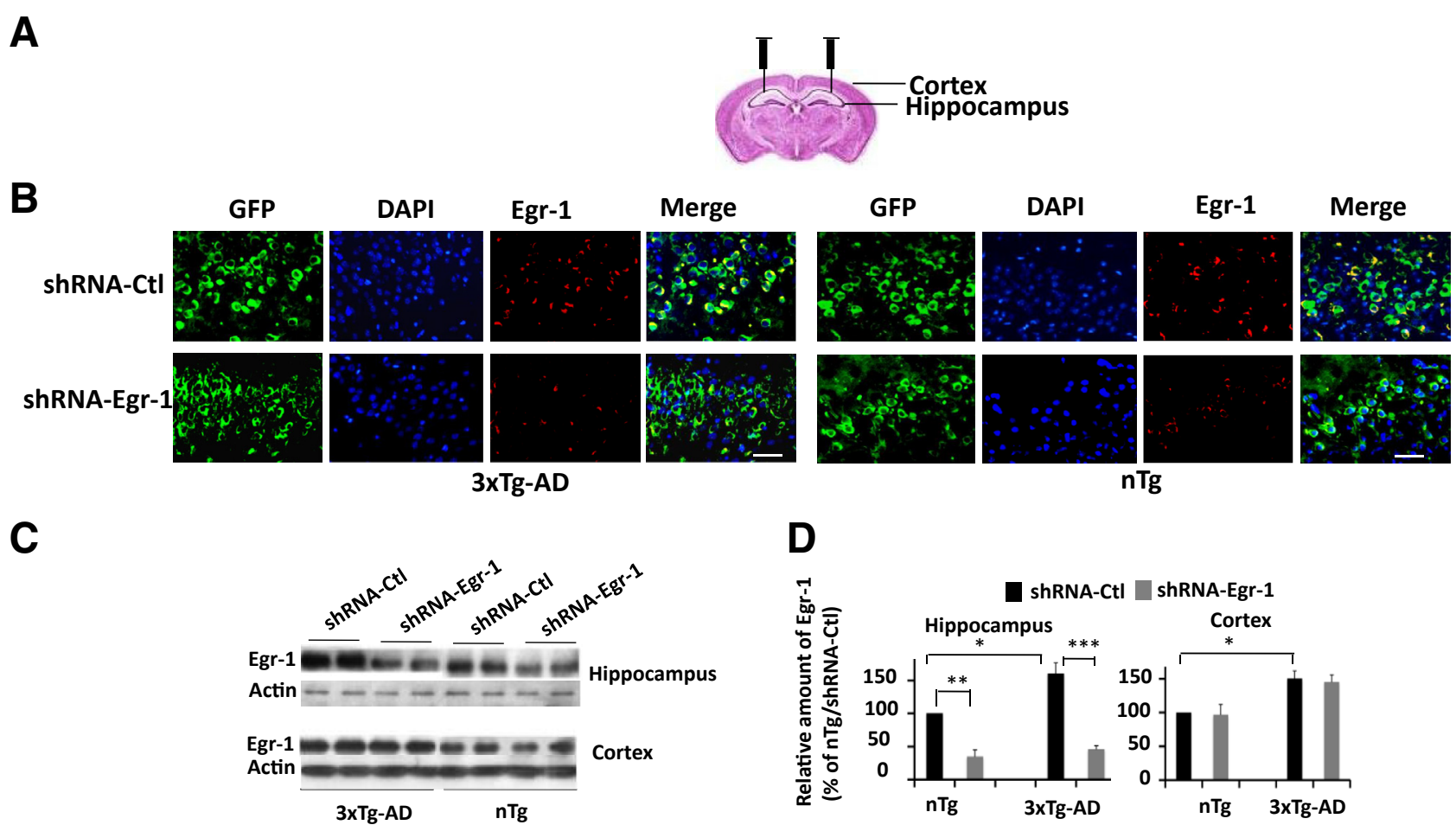

Figure 3 shRNA-Egr-1 delivery reduces Egr-1 level in the hippocampus. The expression of shRNA-Egr-1 and its effect on Egr-1 level were analyzed by immunohistochemistry and Western blot analysis. A: Location of lentivirus injection sites in the hippocampus of mice. B: Confocal micrographs showing expression of GFP (shRNA-Ctl and shRNA-Egr-1) in the hippocampus. Note that Egr-1 immunostaining is significantly reduced in hippocampus expressing shRNA-Egr-1 in both nTg and 3xTg-AD mice. C: Western blots showing Egr-1 levels in the hippocampus expressing shRNA-Egr-1. D: Quantification of Western blots. Data expressed as average \pm SEM. $n=12$ mice per genotype; $n=6$ mice per group. ${ }^{\star} P<0.05,{ }^{*} P<0.01$, and ${ }^{* *} P<0.005$ (one-way analysis of variance and Newman-Keuls post hoc analysis). Scale bars $=80 \mu \mathrm{m}(\mathbf{B})$.

phosphatases. shRNA-Egr-1 did not affect tau phosphorylation at $\mathrm{Ser}^{214}$ (Figure 4, A and B), which is phosphorylated by protein kinase A, Cam kinase 2, and protein kinase C. ${ }^{14,44}$ Likewise, the levels of PP2A and inactive tyrosine phosphorylated pPP2A were comparable between the two groups (Figure 5). These data are consistent with the previous report ${ }^{32}$ and showed that Egr-1 does not affect tau phosphorylation/dephosphorylation by protein kinase A, Cam kinase 2, protein kinase C, and PP2A.

Cdk5 is one of the major kinases that phosphorylate tau in the brain. ${ }^{14}$ It is composed of a catalytic Cdk5 subunit and an activating p35 subunit. Furthermore, p35 is proteolyzed to p25 protein in vivo. Cdk5 bound to p25 is more active than that bound to $\mathrm{p} 35{ }^{45}$ Egr-1 activates Cdk5 by inducing transcription of $\mathrm{p} 35^{43}$ and thus promotes tau phosphorylation in the brain. ${ }^{32}$ In addition, by promoting Cdk5-catalyzed inhibitory PP1 phosphorylation at $\mathrm{Thr}^{321}$, ${ }^{46}$ Egr-1 causes enhancement in tau phosphorylation at $\mathrm{Ser}^{262}$. $^{32}$ Consistent with these findings, shRNA-Egr-1 did not affect the ratio of p25/p35 but reduced levels of p35, pPP1 (Figure 5), and tau phosphorylated at $\mathrm{Ser}^{404}, \mathrm{Ser}^{235}$, $\mathrm{Thr}^{181}$, and $\mathrm{Ser}^{262}$ in both 3xTg-AD and nTg hippocampi (Figure 4, A and B). However, shRNA-Egr-1 also reduced tau phosphorylation at $\mathrm{Thr}^{231}$ (Figure 4B). Interestingly, among all tau sites tested, phosphorylation at $\mathrm{Thr}^{231}$ is highest in the hippocampus of $3 \times$ Tg-AD mice (Figure 4A). Studies have shown that tau phosphorylation at $\mathrm{Thr}^{231}$ plays a critical role in tau dysfunction associated with $\mathrm{AD}$ and is preferentially phosphorylated by GSK $3 \beta .{ }^{47-50}$ These data suggested that Egr- 1 also regulates tau phosphorylation by GSK3 $\beta$ in the brain.

\section{Egr-1 Regulates Tau Phosphorylation by GSK3 $\beta$ in Neurons}

Egr-1 does not directly affect GSK3 $\beta$ activity, ${ }^{32}$ and the levels of total and Ser $^{9}$-phosphorylated inactive GSK3 $\beta$ were unaltered in shRNA-Egr-1 and shRNA-Ctl injected mice (Figure 5). However, a unique feature of GSK3 $\beta$ is that it phosphorylates some of its substrates only when the substrate is previously phosphorylated (primed) by another kinase. ${ }^{49}$ Previous studies have shown that Cdk5 phosphorylates tau at $\operatorname{Ser}^{235}$ first. GSK3 $\beta$ subsequently phosphorylates $\mathrm{Ser}^{235}$-phosphorylated tau at $\mathrm{Thr}^{231}$. ${ }^{28,49}$ Therefore, it is possible that shRNA-Egr-1 may have reduced tau $\mathrm{Thr}^{231}$ phosphorylation in the hippocampus of $3 \times \mathrm{Tg}-\mathrm{AD}$ mice by inhibiting Cdk5 action and thus preventing tau priming. If so, Egr-1-induced $\mathrm{Thr}^{231}$ phosphorylation will be expected to be dependent on actions of both Cdk5 (for $\operatorname{Ser}^{235}$ phosphorylation) and GSK3 $\beta$ (for $\mathrm{Thr}^{231}$ phosphorylation). To test this idea, we infected rat hippocampal primary neurons with Ln-Egr-1 on Ln-vector and analyzed infected neurons (Figure 6). Egr-1 activated 
A

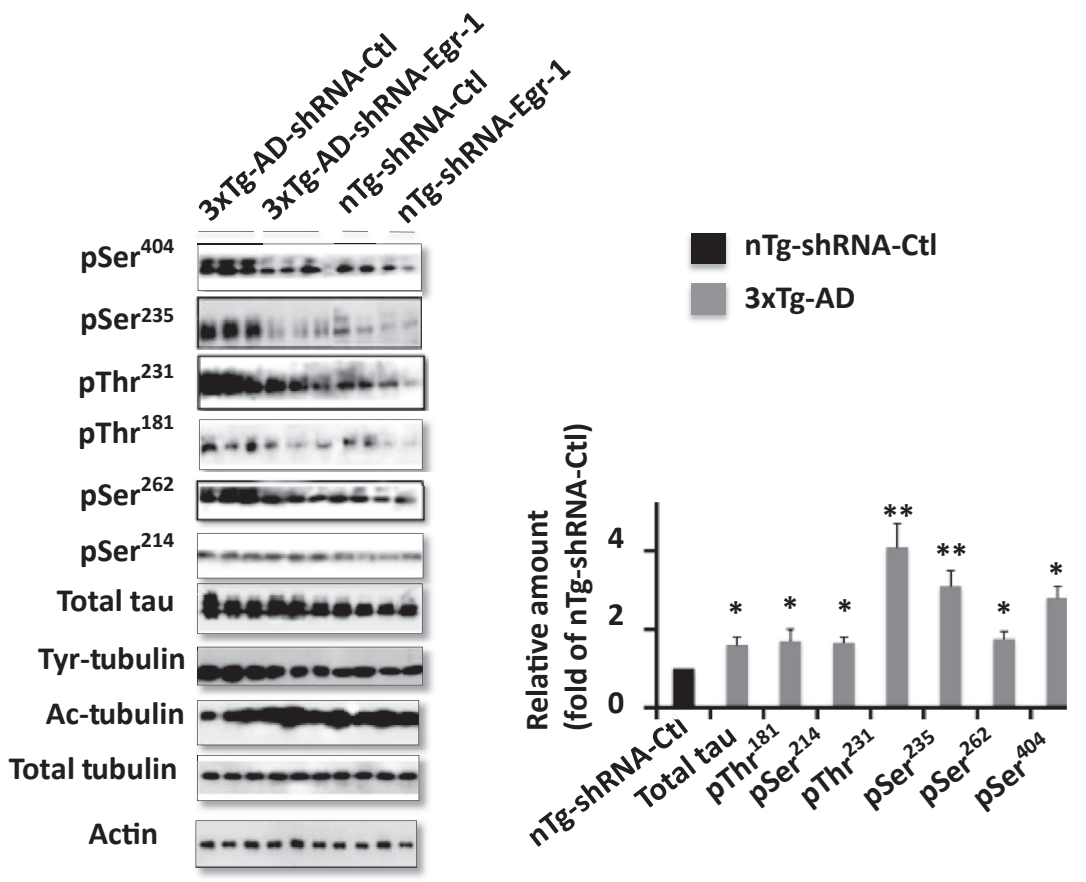

B

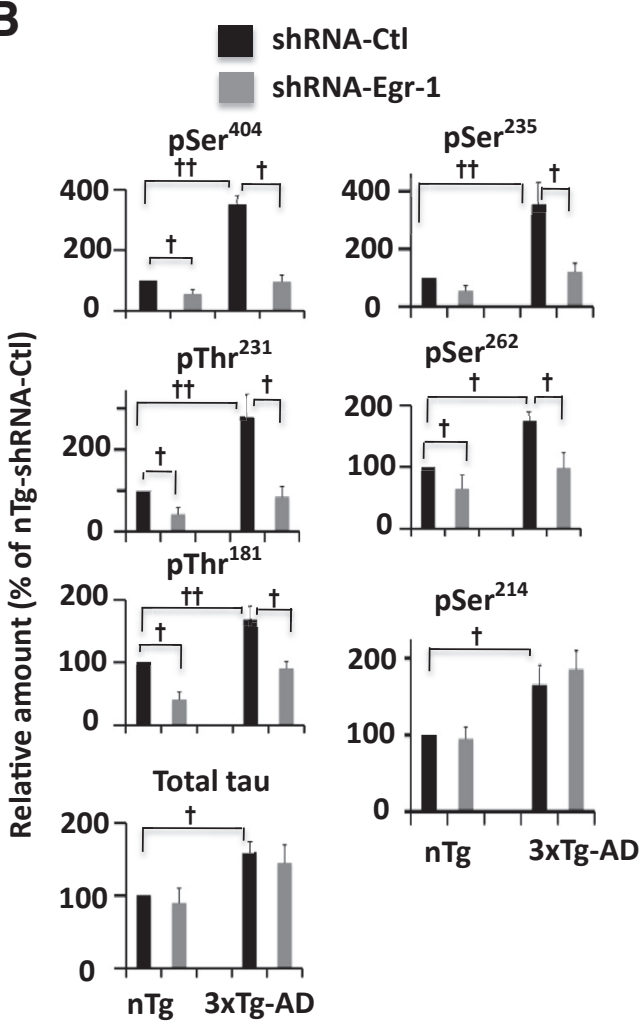

C

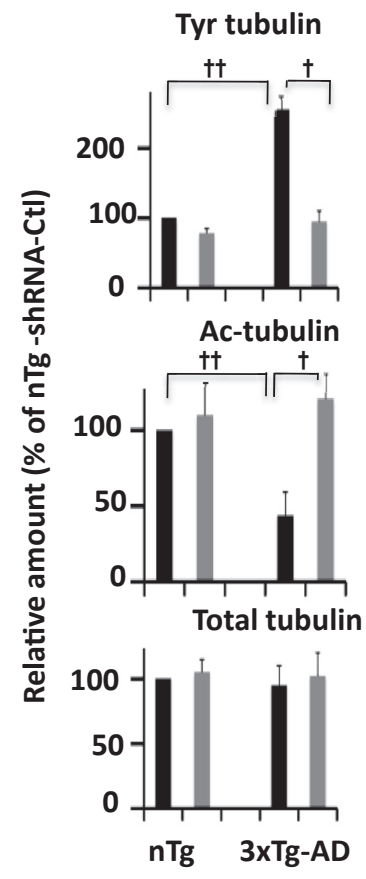

Figure 4 Inhibition of Egr-1 by shRNA reduces tau phosphorylation and stabilizes microtubules in the hippocampus. Hippocampal extracts of $3 \times \mathrm{Tg}$ $A D$ and $n T g$ mice receiving shRNA-Egr-1 and shRNA-Ctl were analyzed for tau phosphorylation and microtubule stability by Western blot analyses. A: Representative Western blots and a comparison of total and phosphorylated tau in the hippocampus of $3 \times \mathrm{Tg}-\mathrm{AD}$ and $\mathrm{nTg}$ mice. Left panel shows representative Western blots; right panel, quantification. B and C: Quantification of Western blot data showing effects of shRNA-Egr-1 on tau phosphorylation and microtubule stability in the hippocampus of $3 \times \mathrm{Tg}-\mathrm{AD}$ and $\mathrm{nTg}$ mice. For quantification, total tau band was normalized against respective actin. To quantify tau phosphorylation, phosphorylated tau band intensity was normalized against corresponding total tau bands. Total tubulin band was normalized against actin, whereas Tyr-tubulin band, representing unstable microtubule, and Ac-tubulin bands, representing stable microtubules, were normalized against corresponding total tubulin bands. Data are expressed as means $\pm \mathrm{SEM}(\mathbf{A}-\mathbf{C}) \cdot n=12$ mice per genotype; $n=6$ mice per group. ${ }^{*} P<0.05,{ }^{* * *} P<0.005$ (one-way analysis of variance and Newman-Keuls post hoc analysis); ${ }^{\dagger} P<0.05,{ }^{\dagger} P<0.01$ (one-way analysis of variance and Newman-Keuls post hoc analysis).
$\mathrm{Cdk} 5$, whereas the activity of GSK3$\beta$ remained at the basal level in Ln-Egr-1 infected neurons (Figure 6C). These data are as expected and showed that Egr-1 activates Cdk5 and has no effect on GSK3 $\beta$ activity. Inhibition of Cdk5 by roscovitine blocked tau phosphorylation at both $\mathrm{Thr}^{231}$ and $\operatorname{Ser}^{235}$ (Figure 6, A and B). Inhibition of GSK3 $\beta$ by lithium chloride, on the other hand, inhibited only $\mathrm{Thr}^{231}$ phosphorylation (Figure 6B). Thus, Egr-1 promotes tau phosphorylation at $\mathrm{Ser}^{235}$ and $\mathrm{Thr}^{231}$. Egr-1-induced phosphorylation at $\mathrm{Ser}^{235}$ is $\mathrm{Cdk} 5$ dependent. Egr-1-induced 

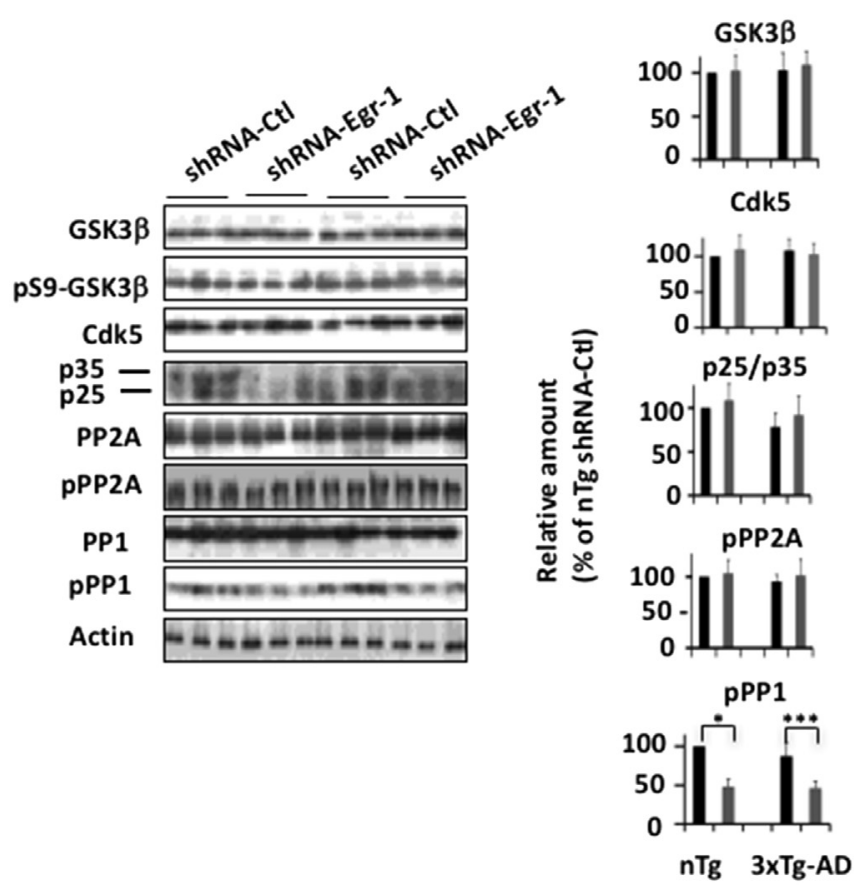
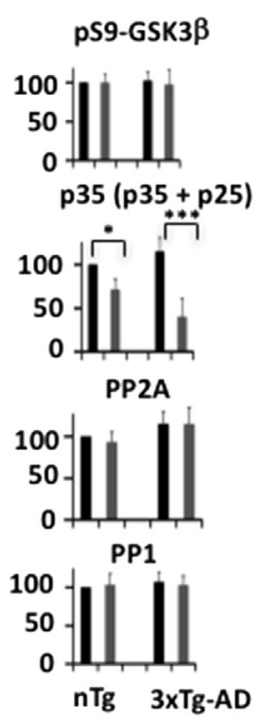

ShRNA-CtI

ShRNA-Egr-1
Figure 5 Inhibition of Egr-1 reduces level of p35 subunit of Cdk5 in the hippocampus of $3 \times \mathrm{Tg}$ $A D$ mice. Representative Western blots and their quantification. For quantification, GSK3 $\beta$, Cdk5, PP1, and PP2A bands were normalized against corresponding actin bands. $\mathrm{pS}^{9}-\mathrm{GSK} 3 \beta, \mathrm{pT}^{320} \mathrm{PP} 1$, and $\mathrm{PY}-\mathrm{PP} 2 \mathrm{~A}$ bands were normalized against corresponding total protein bands. Total p35 is the sum of p35 and p25 normalized against corresponding actin band. Data are expressed as average \pm SEM. $n=12$ mice per genotype; $n=6$ mice per group. ${ }^{*} P<0.05,{ }^{* *} P<0.005$ (oneway analysis of variance and Newman-Keuls post hoc analysis). phosphorylation of $\mathrm{Thr}^{231}$, on the other hand, is dependent on the activities of both Cdk5 and GSK3 $\beta$. Moreover, in cells treated with lithium chloride, $\mathrm{Cdk} 5$ was active but $\mathrm{Thr}^{231}$ phosphorylation was blocked (Figure 6, A and B). This indicates that Cdk5 does not phosphorylate $\mathrm{Thr}^{231}$ in neurons.

Inhibition of Egr-1 Reduces $A \beta$ Pathology in the Hippocampus of $3 \times \mathrm{Tg}-\mathrm{AD}$ Mice

3xTg-AD mice displayed extensive $\mathrm{A} \beta 42$ immunoreactive plaques in both the hippocampus and the cortex (Figure 7A). Interestingly, compared to 3xTg-AD-shRNACtl controls, 3xTg-AD-shRNA-Egr-1 mice had 57.1\% fewer plaques in the hippocampus (Figure 7A). Moreover, the level of soluble A $\beta 42$ was $84.9 \%$ lower in the hippocampus of 3xTg-AD-shRNA-Egr-1 than 3xTg-AD-shRNACtl mice (Figure 7B). Likewise, 3xTg-AD-shRNA-Egr-1 mice had soluble A $\beta 4078 \%$ lower in the hippocampus than $3 \times$ Tg-AD-shRNA-Ctl mice. This effect was not observed in the cortex, which did not receive shRNA injection (Figure 7). These data determined that inhibition of Egr-1 also reduces $A \beta$ pathology in $3 \times \mathrm{Tg}-\mathrm{AD}$ mice.

\section{Inhibition of Egr-1 Down-Regulates BACE-1 Level in} the Hippocampus

$\mathrm{A} \beta$ level in the brain is mainly controlled by its production and clearance. The proteolytic degradation is a major route of $\mathrm{A} \beta$ clearance. ${ }^{51}$ Neprilysin and insulin-degrading enzyme are among the main $A \beta$-degrading enzymes in the brain. ${ }^{51-53}$ Levels of both neprilysin and insulindegrading enzyme were similar in all experimental groups (Figure 8A). These data indicated that levels of neprilysin and insulin-degrading enzyme are not altered in 3xTg-AD mice and injection of shRNA-Egr-1 does not affect levels of these enzymes in the hippocampus.

$\mathrm{A} \beta$ is produced by a sequential cleavage of APP by BACE-1 and $\gamma$-secretase, a multimeric enzyme with PS1 or PS2 being the catalytic subunit. ${ }^{2,54}$ Western blot analysis showed that compared to nTg-shRNA-Ctl, the level of PS1 was 1.45 -fold higher in 3xTg-AD-shRNA-Ctl mice (Figure 8A). The level of PS2, on the other hand, was similar in the two groups. More important, levels of both PS1 and PS2 were comparable in 3xTg-AD-shRNA-Egr-1 and 3xTgAD-shRNA-Ctl mice. A similar observation was made in the nTg mice. This result determined that inhibition of Egr-1 does not affect levels of PS1 and PS2 in the hippocampus.

We then analyzed the level of BACE-1. 3xTg-ADshRNA-Egr-1 mice had a BACE-1 level $60.1 \%$ lower than 3xTg-AD-shRNA-Ctl mice in the hippocampus (Figure 8B). Likewise, in the hippocampus of nTg-shRNA-Egr-1 mice, the BACE-1 level was $55.2 \%$ of nTg-shRNA-Ctl. This effect was not apparent in the cortex of both genotypes, which did not receive viral injection. Immunohistochemical data showed that compared to shRNA-Ctl-injected animals, the level of BACE-1 in shRNA-Egr-1-injected counterparts was $35.2 \%$ lower in $3 \times \mathrm{Tg}-\mathrm{AD}$ and $25.3 \%$ lower in $\mathrm{nTg}$ (Figure 8C). Again, no such effect on BACE-1 level was observed in the cortex.

In the brain, APP is cleaved by either $\alpha$-secretase or BACE-1, followed by $\gamma$-secretase. BACE-1 cleavage generates $\mathrm{C}$-terminal C99 and $\mathrm{N}$-terminal sAPP $\beta$. $\alpha$-Secretase cleavage, on the other hand, generates $\mathrm{C} 83$ and $\operatorname{sAPP} \alpha^{2}$. The levels of both C99 and sAPP $\beta$ were $45.3 \%$ and $58.9 \%$ lower, respectively, in 3xTg-AD-shRNA-Egr-1 mice when compared to the 3xTg-AD-shRNA-Ctl cohort (Figure 9A). 

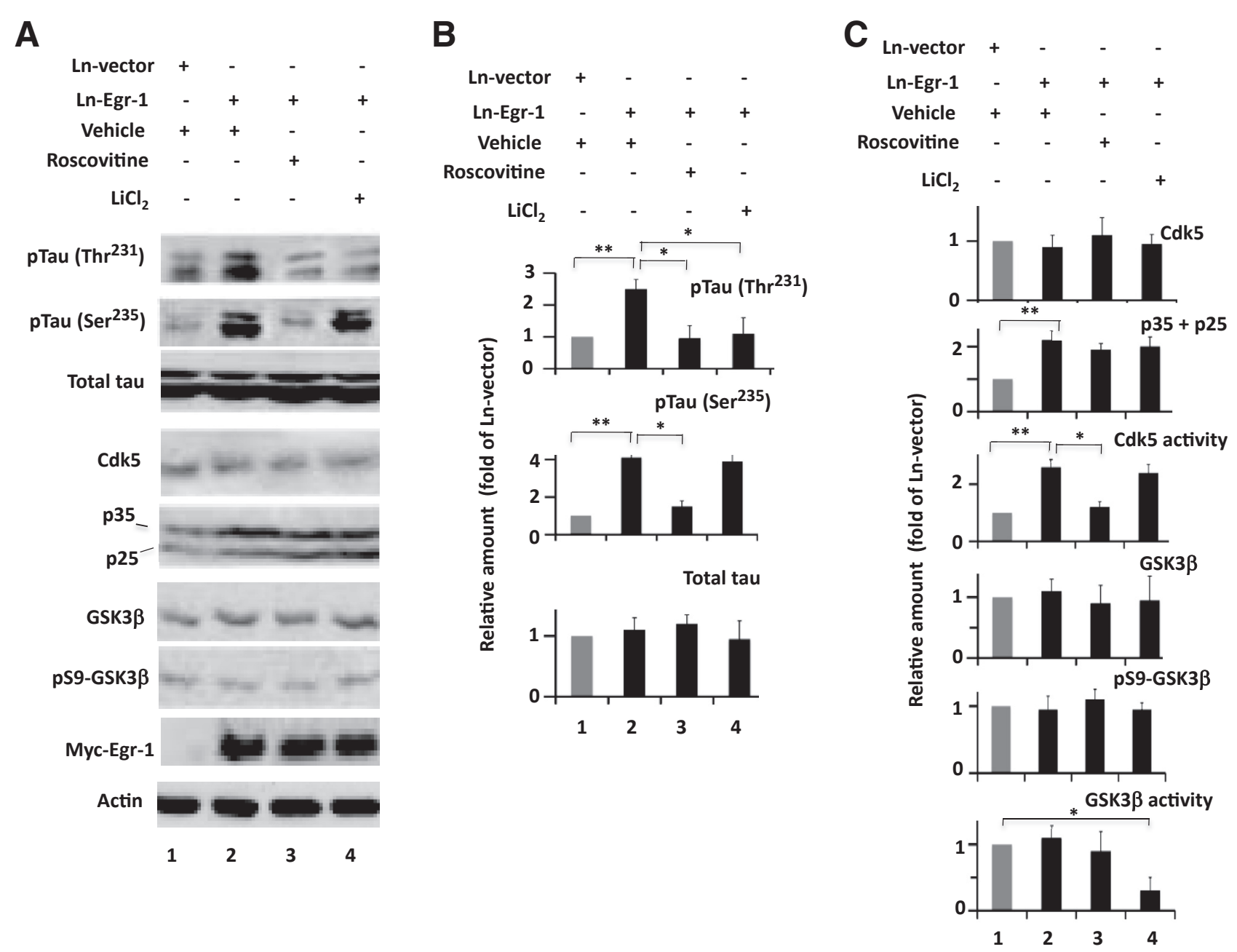

Figure 6 Egr-1-promoted tau phosphorylation at Thr ${ }^{231}$ requires activities of both Cdk5 and GSK3ß. Rat hippocampal primary neurons infected with LnEgr-1 or Ln-vector for 48 hours were treated with $400 \mathrm{nmol} / \mathrm{L} \mathrm{Cdk5}$ inhibitor roscovitine, $10 \mathrm{mmol} / \mathrm{L} \mathrm{GSK3} \beta$ inhibitor lithium chloride (LiCl $\left.{ }_{2}\right)$, or vehicle for 15 minutes. Treated neurons were then analyzed by Western blotting for proteins and activity assays for Cdk5 and GSK3 $\beta$. A: Representative Western blots. B and C: Quantification. Data are expressed as means \pm SEM. $n=3$ independent experiments using independent cultures $(\mathbf{B}$ and $\mathbf{C})$. ${ }^{*} P<0.05,{ }^{* *} P<0.01$ (one-way analysis of variance and Newman-Keuls post hoc analysis).

The level of C83, on the other hand, was similar in the two experimental groups. The amount of C99/C83 ratio, which is an indicator of amyloidogenic APP metabolism, was $47.8 \%$ lower in 3xTg-AD-shRNA-Egr-1 than 3xTg-ADshRNA-Ctl (Figure 9A). Similar observations were made in nTg littermates. Thus, shRNA-Egr-1 reduced levels of BACE-1 and BACE-1-cleaved APP metabolites (sAPP $\beta$ and C99) and lowered the $\mathrm{C} 99 / \mathrm{C} 83$ ratio in the hippocampus.

The above data suggested that Egr-1 is either an activator or a stabilizer of BACE-1. To substantiate the hippocampal data and to evaluate the above possibilities, we infected hippocampal primary neurons with shRNA-Egr-1 or shRNA-Ctl and analyzed them. In neurons infected with shRNA-Egr-1, the level of Egr-1 was $72.2 \%$ lower when compared to those infected with shRNA-Ctl (Figure 9B). The level of BACE-1 was also $64.2 \%$ lower in neurons infected with shRNA-Egr-1 than those infected with shRNA-Ctl. Thus, as in the hippocampus, knockdown of
Egr-1 reduced BACE-1 level in neurons. We then infected neurons with Ln-Egr-1 or Ln-vector. Western blot analysis showed that neurons overexpressing Egr-1 had a 1.9-fold higher level of BACE-1 protein that those expressing vector (Figure 9C). Likewise, BACE-1 immunostaining was 1.8-fold higher in neurons expressing Ln-Egr-1 than those expressing Ln-vector (Figure 9C). This result determined that Egr-1 is an activator of BACE-1 in neurons.

\section{Egr-1 Activates Cdk5 and BACE-1 via a Transcriptional Mechanism}

Egr-1 is a transcription factor and regulates expressions of target genes by binding to their promoters. To determine the mechanism by which Egr-1 activates Cdk5 and BACE-1, we infected rat hippocampal primary neurons with Ln-Egr-1 or Ln-vector and analyzed them (Figure 10, A and B). Western blot and qPCR analyses showed that compared to Ln-vector-infected neurons, Ln-Egr-1-infected neurons 
A

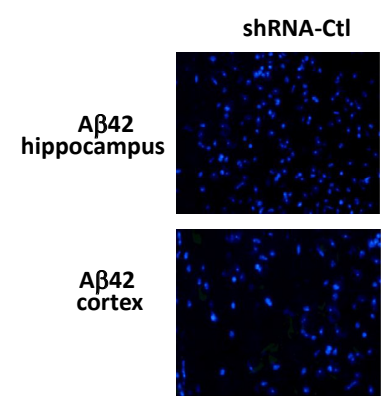

$\mathrm{nTg}$
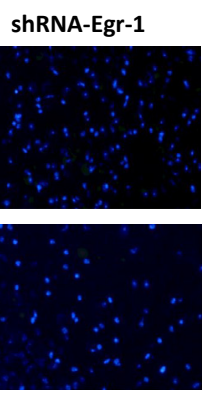

3xTg-AD

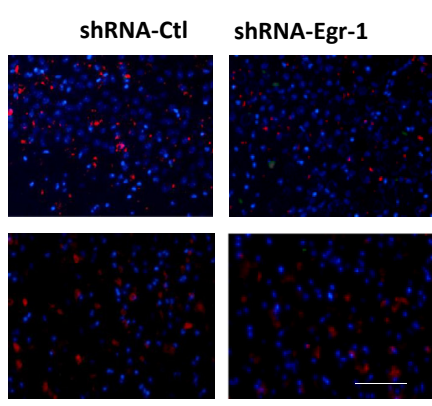

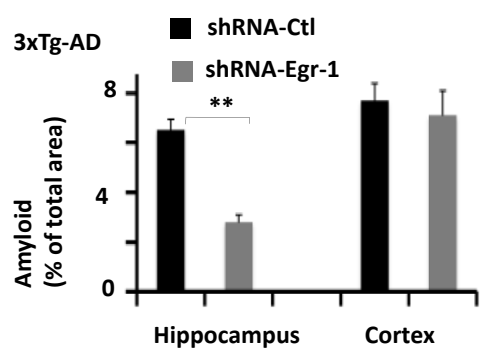

B
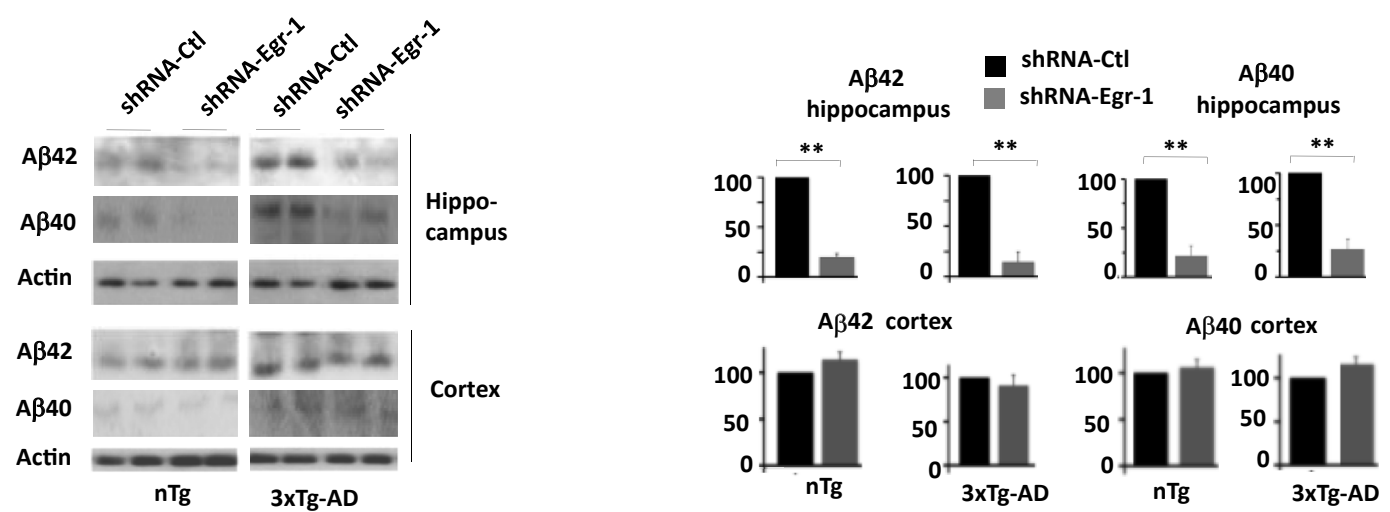

Figure 7 Inhibition of Egr-1 by shRNA reduces A $\beta$ pathology in the hippocampus of 3xTg-AD mice. The hippocampus and cortex of 3xTg-AD and $n T g$ mice receiving shRNA-Ctl and shRNA-Egr-1 were analyzed by immunohistochemistry and Western blotting. A: Immunohistochemistry. Representative confocal images of hippocampus and cortex of $3 \times \mathrm{Tg}-\mathrm{AD}$ and $\mathrm{nTg}$ mice, showing plaques. DAPI (blue) stained brain slices were counterimmunostained with human $\mathrm{A} \beta 42$ antibody. Abundant AB42-positive plaques are seen in both the hippocampus and the cortex of 3xTg-AD mice. A significant reduction in plaques is observed in the hippocampus of 3xTg-AD receiving shRNA-Egr-1 when compared to 3xTg-AD hippocampus receiving shRNA-Ctl. Quantification of immunohistochemical staining was performed using Spectrum Analysis algorithm package and ImageScope analysis software version 11.2 (Aperio Technologies). Data are expressed as the area of hippocampus or cortex occupied by $A \beta$ immunoreactivity. One-way analysis of variance and Newman-Keuls post hoc analysis were performed. B: Western blot analysis. Samples were separated on $4 \%$ to $20 \%$ gradient Tricine gel (Invitrogen). Western blotting was performed using anti-A 40 or anti-A 342 antibody. $t$-Test was performed. Data are expressed as means \pm SEM. $n=12$ randomly selected micrographs from 12 animals in each genotype (A); $n=6$ per group (A); $n=12$ animals per genotype (B); $n=6$ per group $(\mathbf{B})$. ${ }^{*} P<0.01$. Scale bar $=50 \mu \mathrm{m}(\mathbf{A})$.

had 1.9-fold more BACE-1 protein and 2.1-fold higher BACE-1 mRNA. Likewise, Ln-Egr-1-expressing neurons showed 2.6- and 2.1-fold higher p35 protein and mRNA, respectively, in Ln-vector-infected neurons. The level of Cdk5 protein was comparable between the two groups. This result determined that in neurons, overexpression of Egr-1 induces expressions of BACE- 1 and the p35 subunit of Cdk5.

We next performed a chromatin immunoprecipitation assay of infected neurons using antibody against Egr-1 and primers flanking the Egr-1 binding site on promoter of $B A C E 1^{42}$ or $\mathrm{p} 35^{43}$ (Table 1). We observed 5.6-fold BACE1 promoter amplification from anti-Egr-1 antibody than from IgG control (Figure 10B). More important, compared to Ln-vector-infected neurons, Ln-Egr-1-infected neurons had 5.2-fold higher BACE1 promoter amplification (Figure 10B). Likewise, neurons expressing Ln-Egr-1 displayed 6.3-fold more p35 promoter amplification than from Ln-vector-infected neurons (Figure 10C). This result showed that compared to Ln-vector-infected neurons, those infected with Ln-Egr-1 had 5.2- and 6.3-fold more Egr-1 bound to BACE1 promoter and p35 promoter, respectively. Based on this result, we concluded that Egr-1 is a transcriptional activator of BACE-1 and p35 in neurons.

\section{Egr-1 Activates BACE-1 and Promotes APP Processing Independent of $\mathrm{Cdk} 5$ and GSK3 $\beta$}

Silencing Egr-1 in the hippocampus of both $\mathrm{nTg}$ and $3 \mathrm{xTg}$ AD mice reduced levels of BACE-1 and amyloidogenic APP metabolites (sAPP $\beta, C 99, A \beta 40$, and A $\beta 42$ ). Overexpression of Egr-1 in the hippocampal primary neurons activated BACE-1. These data suggested that Egr-1 promotes amyloidogenic APP processing via activating BACE-1. However, Cdk5 was reported to activate BACE-1 and promote aberrant APP processing. ${ }^{5-57}$ Likewise, inhibition of GSK3 $\beta$ was reported to inhibit BACE-1 expression in 20E3 cells. ${ }^{58}$ Egr-1 activates Cdk5 by inducing transcription of $\mathrm{p} 35,{ }^{43}$ whereas Cdk5 primes tau for GSK $3 \beta .^{49}$ Therefore, to determine whether Egr-1 promotes APP processing via BACE-1, Cdk5, or GSK3 $\beta$, we treated mouse hippocampal primary neurons infected with Ln-Egr-1 or Ln-vector with 
A
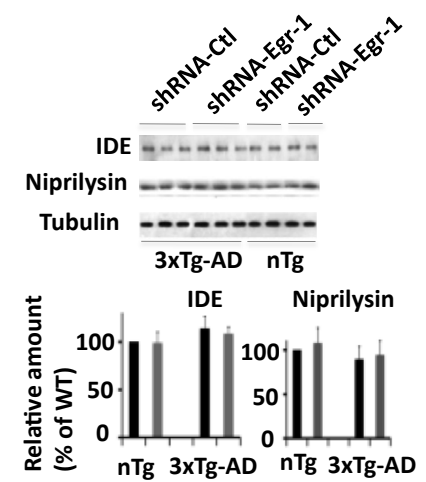

B
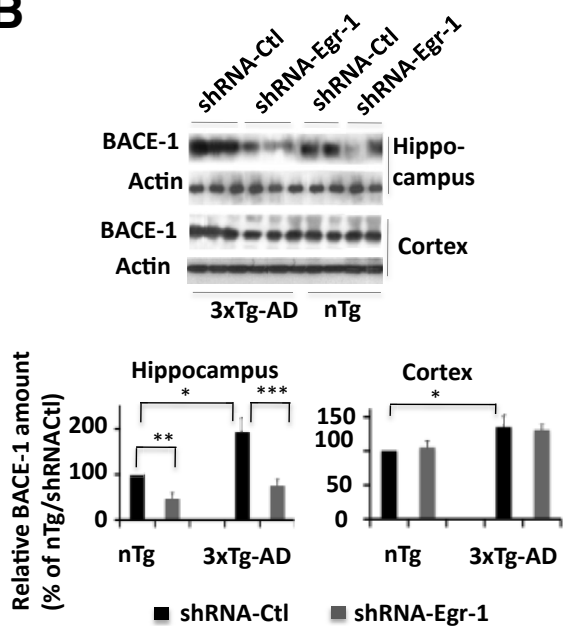

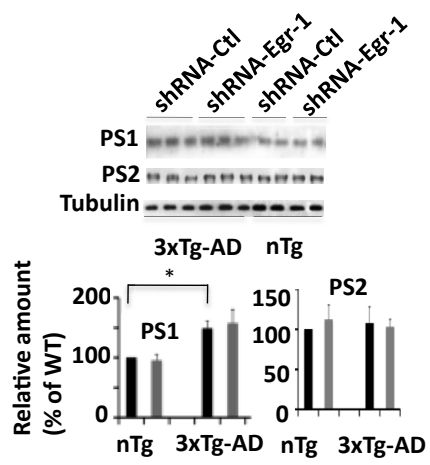

C
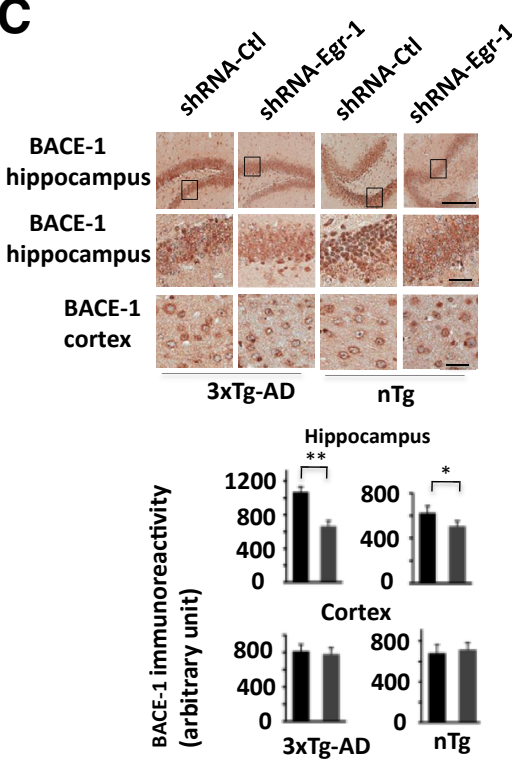

Figure 8 Inhibition of Egr-1 by shRNA downregulates BACE-1 in the hippocampus. A: Left panels: Effect of inhibition of Egr-1 on the levels of enzymes involved in $A \beta$ degradation. Western blot analysis of insulin-degrading enzyme (IDE) and neprilysin. Right panels: Western blot analysis of PS1 and PS2. One-way analysis of variance and Newman-Keuls post hoc analysis were performed. B: Inhibition of Egr-1 down-regulates BACE-1. Western blot and quantification of BACE1. One-way analysis of variance and NewmanKeuls post hoc analysis were performed. C: Top panel: Immunohistochemistry. Micrographs of hippocampus and cortex. Higher-magnification images of the boxed areas (top row) of hippocampus (middle row) and cortex (bottom row) show BACE-1 in hippocampus and cortex of $\mathrm{nTg}$ and $3 \times \mathrm{Tg}-\mathrm{AD}$ mice. Middle and bottom panels: Quantification of immunohistochemical staining, which was performed using Spectrum Analysis algorithm package and ImageScope analysis software version 11.2 (Aperio Technologies). One-way analysis of variance and $t$-test were performed. Data are expressed as means \pm SEM. $n=12$ mice per genotype (A); $n=6$ mice per group (A and B) $; n=12$ randomly selected micrographs of 12 mice per genotype (C); $n=6$ mice per group (C, middle and bottom panels). Scale bars: $500 \mu \mathrm{m}$ (C, top row); $50 \mu \mathrm{m}$ (C, middle row); $20 \mu \mathrm{m}$ (C, bottom row). ${ }^{\star} P<0.05,{ }^{*} * P<0.01$, and ${ }^{* * *} P<0.005$
Cdk5 inhibitor rocovitine or GSK3 $\beta$ inhibitor lithium chloride and analyzed them (Figure 11).

A kinase activity assay determined that compared to neurons infected with Ln-vector, those infected with LnEgr-1 had 2.5-fold higher Cdk5 activity, but the GSK3 $\beta$ activity was comparable (Figure 11B). Tau phosphorylation was 2.8- and 2.5-fold higher at $\mathrm{Ser}^{396 / 404}$ and $\mathrm{Thr}^{231}$, respectively, in neurons overexpressing Ln-Egr-1 than those expressing Ln-vector. Roscovitine inhibited Egr-1-induced Cdk5 activity but showed no effect on GSK3 $\beta$ activity. Egr-1-induced tau phosphorylations at $\mathrm{Ser}^{396 / 404}$ and $\mathrm{Thr}^{231}$ were almost completely inhibited by roscovitine. Lithium chloride inhibited GSK3 $\beta$ activity and tau phosphorylation on $\mathrm{Thr}^{231}$, but had no effect on Cdk5 activity and tau phosphorylation at Ser ${ }^{396 / 404}$. Thus, Egr-1 activated Cdk5 and promoted tau phosphorylation at $\operatorname{Ser}^{396 / 404}$ and $\mathrm{Thr}^{231}$ (Figure 6). Blocking Cdk5 action blocked phosphorylation at both $\mathrm{Ser}^{396 / 404}$ and $\mathrm{Thr}^{231}$. Egr-1 did not activate GSK3 $\beta$, but blocking GSK3 $\beta$ action blocked tau phosphorylation at $\mathrm{Thr}^{231}$.

We next analyzed BACE-1 and APP processing (Figure 11, A and C). Western blot analysis showed that compared to Ln-vector-infected neurons, BACE-1 protein level was 1.8-fold higher in Ln-Egr-1-infected neurons. A fluorogenic BACE-1 activity assay substantiated Western data and determined that BACE-1 activity was 1.7 -fold higher in neurons expressing Ln-Egr-1 than those expressing Ln-vector (Figure 11C). Moreover, compared to Ln-vector-infected neurons, those infected with Ln-Egr-1 had 3.3fold more BACE-1-cleaved C99 but a comparable level of $\alpha$-secretase-specific C83. Similarly, Ln-Egr-1-infected neurons secreted 1.9- and 1.5-fold more sAPP $\beta$ and A $\beta 42$, respectively, in medium than those infected with Ln-vector. Thus, overexpression of Egr-1 activated BACE-1 and accelerated amyloidogenic APP processing in mouse hippocampal primary neurons.

Compared to Ln-Egr-1-infected neurons treated with vehicle, $\mathrm{Ln}$-Egr-1-infected neurons treated with roscovitine had comparable levels of BACE-1 protein, BACE-1 activity, C99, sAPP $\beta$, and A $\beta 42$ (Figure 11C). Similar observations were made in Ln-Egr-1-infected neurons treated with lithium chloride or vehicle and Ln-Egr-1-infected neurons treated with roscovitine plus lithium chloride or vehicle. These data indicated that blocking actions of $\mathrm{Cdk} 5$, 


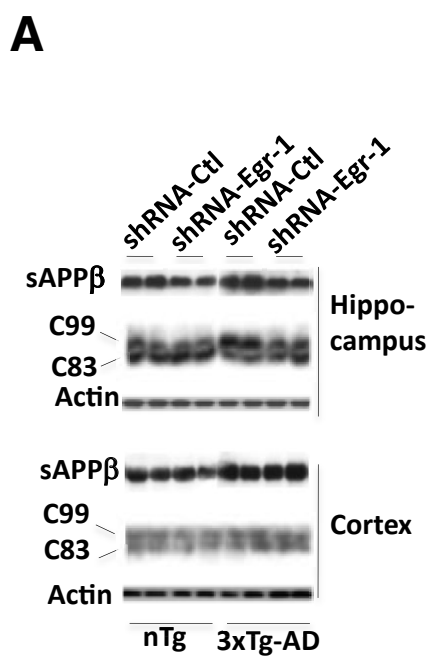

B

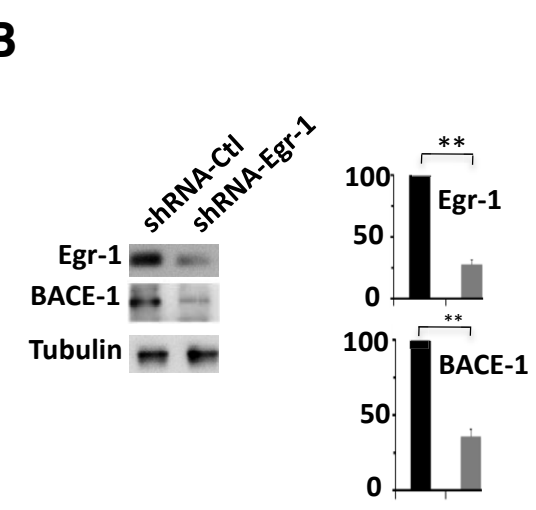

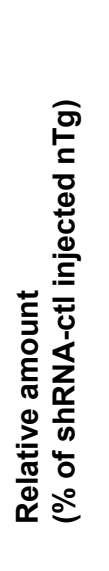
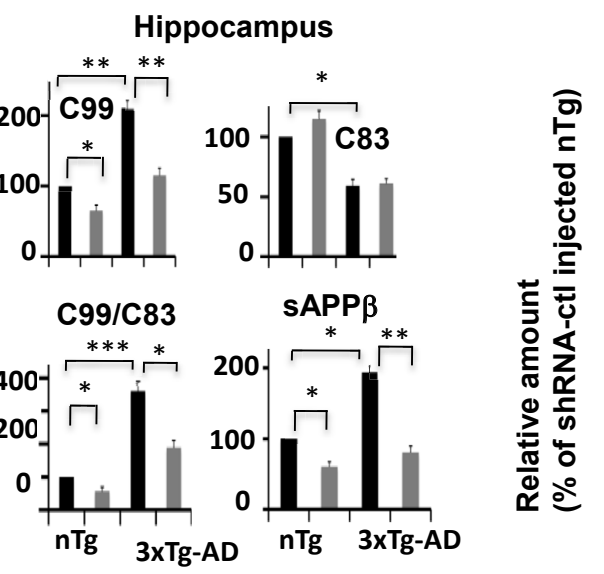

shRNA-ctl ShRNA-Egr-1
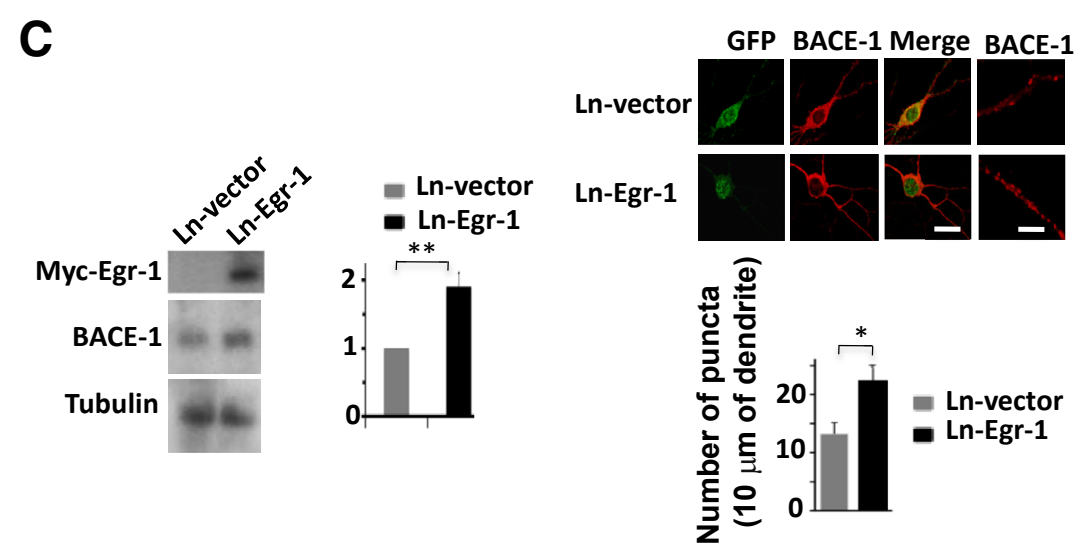

Figure 9 A: Inhibition of Egr-1 by shRNA reduces BACE-1-generated C99 and SAPP $\beta$ in the hippocampus. Hippocampal and cortical extracts of mice injected with shRNA-Egr-1 of shRNA-Ctl were separated either on $8 \%$ SDS gel for SAPP $\beta$ and actin or $4 \%$ to $12 \%$ Bis-Tris gradient gel for C99 and C83. Blots were probed against SAPP $\beta$ or APP-C-terminal antibody. Representative Western blots and their quantification. To determine the C99/C83 ratio, the C99 value of a sample was divided by the $\mathrm{C} 83$ value of that sample. One-way analysis of variance and Newman-Keuls post hoc analysis were performed. B: Inhibition of Egr-1 by shRNA reduces BACE-1 level in mouse hippocampal primary neurons. Mouse neurons infected with shRNA-Egr-1 or shRNA-Ctl were analyzed by Western blotting. $t$-Test was performed. C: Overexpression of Egr-1 up-regulates BACE-1 in hippocampal primary neurons. Mouse hippocampal primary neurons were infected with Ln-Egr-1 or Ln-vector and then analyzed by Western blotting and immunocytochemistry. Western blot analysis. $t$-Test was performed. Immunocytochemistry: GFP shows infected neurons. Quantification of BACE-1 level is from micrographs of 15 randomly chosen infected neurons from four different cultures in each group along at least $30 \mu \mathrm{m}$ of each neurite. $t$-test was performed. Data are expressed as means \pm SEM. $n=12$ mice per genotype $(\mathbf{A}) ; n=6$ mice per group (A); $n=3$ independent cultures (B); $n=4$ independent experiments (C). ${ }^{*} P<0.05, * * P<0.01$, and ${ }^{* * * P}<0.005$. Scale bars: $30 \mu \mathrm{m}$ (C, first, second, and third columns); $2 \mu \mathrm{m}$ (C, fourth column).

GSK3 $\beta$, or both do not affect Egr-1-induced BACE-1 activation and amyloidogenic APP processing in neurons. Based on these data, we concluded that Egr-1-induced BACE-1 activation and amyloidogenic APP processing are independent of Cdk5 and GSK3 $\beta$.

\section{Egr-1 Promotes Tau Phosphorylation Independent of BACE-1 and A $\beta$}

Egr-1 activates Cdk5 and promotes tau phosphorylation in neurons (Figures 4 and 6). Because Cdk5 phosphorylates tau, these data suggested that Egr-1 promotes tau phosphorylation by activating Cdk5. However, Egr-1 also promotes $A \beta$ production (Figure 11). Several studies have shown that $A \beta$ promotes tau phosphorylation by activating intracellular kinases, including Cdk5. ${ }^{59,60}$ Therefore, Egr-1 may promote tau phosphorylation via $\mathrm{A} \beta$. To test this possibility, we silenced BACE-1 by shRNA in neurons infected with Ln-Egr-1 and analyzed them (Figure 12). Compared to neurons infected with Ln-vector and treated with shRNA-Ctl, those infected with Ln-Egr-1 and treated with shRNA-Ctl showed increased BACE-1 level, elevated BACE-1 activity, increased $A \beta 42$, and increased phosphorylated tau, as expected (Figure 12, A-C). More important, neurons infected with Ln-Egr-1 and treated with shRNA-BACE-1 displayed $65 \%$ and $63 \%$ reductions in the levels of BACE- 1 and A $\beta 42$, respectively, when compared to those infected with Ln-Egr-1 and treated with shRNACtl. These data determined that Egr-1 promotes $A \beta$ production via BACE-1. The levels of tau phosphorylated at all 

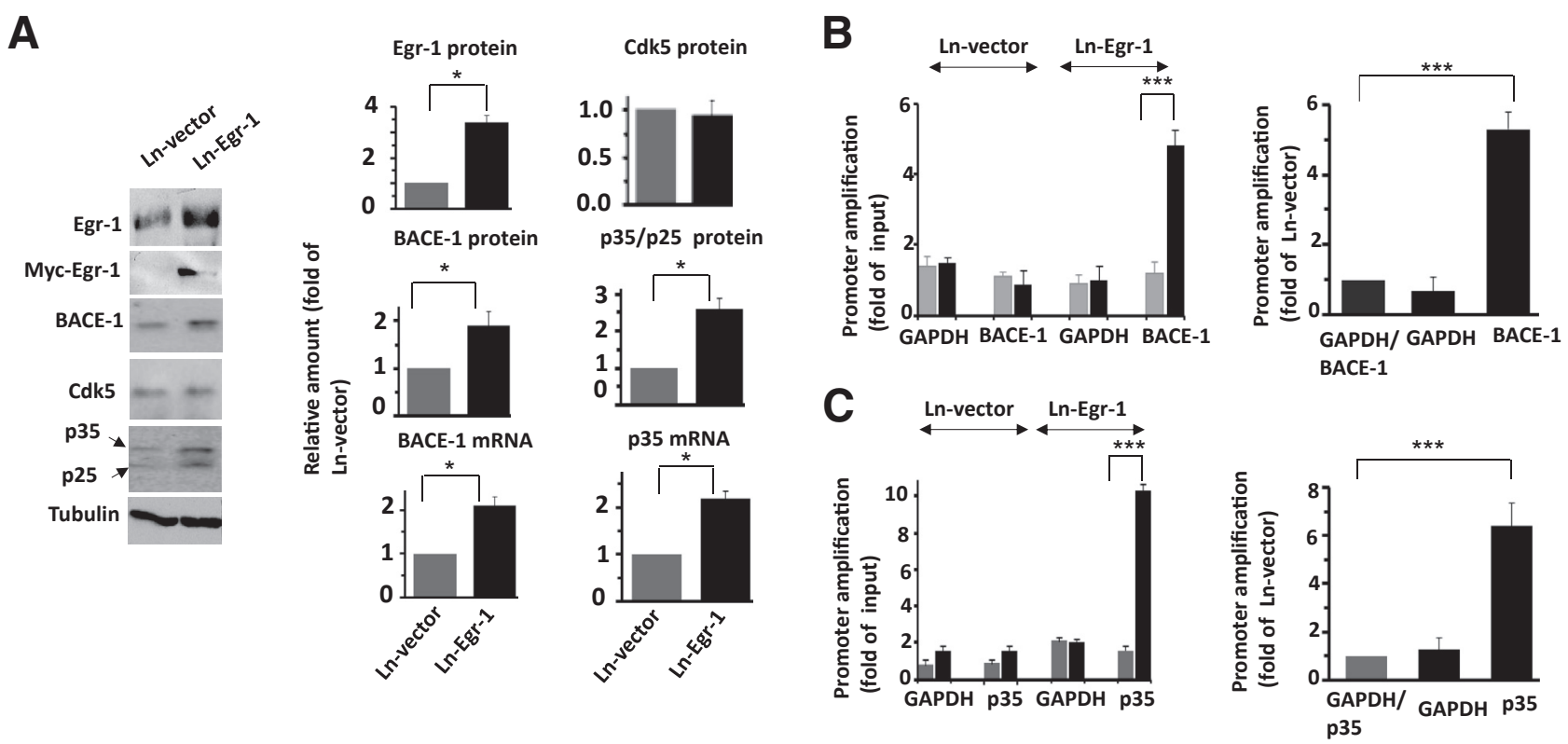

Figure 10 Egr-1 activates BACE-1 and Cdk5 by a transcriptional mechanism. Rat hippocampal primary neurons were infected with Ln-vector of Ln-Egr-1. Infected neurons were analyzed by Western blotting for proteins, qPCR for mRNAs, and chromatin immunoprecipitation (ChIP) assay for promoter binding. A: Western blotting, qPCR, and quantification. B: ChIP assay for BACE1 promoter. Neurons infected with Ln-Egr-1 or Ln-vector were immunoprecipitated using anti-Egr-1 or IgG. BACE1 promoter in the immunoprecipitate was amplified by qPCR using primers specific to Egr-1-binding site of BACE1 promoter (Table 1). Glyceraldehyde-3-phosphate dehydrogenase (GAPDH) was amplified as the internal control. Bar graphs were generated from qPCR data. BACE1 promoter amplification between Ln-vector- and Ln-Egr-1-infected neurons. To make the comparison, the qPCR value obtained for the IgG from the ChIP data of a sample was subtracted from the corresponding value for the anti-Egr-1. Resulting values were used to generate the graph. Values are the average of three determinations. C: ChIP assay for p35 promoter. ChIP assay was performed as in B except primers flanking p35 promoter were used. Data are expressed as average $\pm \operatorname{SEM}(\mathbf{A}) . n=3$ independent cultures $(\mathbf{A}) ; n=4$ independent cultures (B). ${ }^{*} P<0.05,{ }^{* *} P<0.005$ ( $t$-test).

sites examined were comparable in neurons infected with Ln-Egr-1 and treated with shRNA-BACE-1 and those infected with Ln-Egr-1 and treated with shRNA-Ctl. Furthermore, activities of both Cdk5 and GSK3 $\beta$ were also similar between the two groups (Figure 12D). Thus, blocking BACE-1 action blocked Egr-1-induced A $\beta$ production but had no effect on tau phosphorylation and activities of Cdk5 and GSK3 $\beta$. This result determined that Egr-1 promotes tau phosphorylation independent of BACE-1 and A $\beta$.

\section{Discussion}

The accumulation of $A \beta$ and hyperphosphorylated tau in the brain is regarded as central to AD pathogenesis. ${ }^{1,2}$ So far, all of the $A \beta$ - or tau-targeted therapies have been unsuccessful in clinical trials. ${ }^{1}$ The reasons for these failures are not completely clear. However, $A \beta$ and tau pathologies coexist in $\mathrm{AD}$, and $\mathrm{A} \beta$ induces tau filament formation in mouse brain. ${ }^{61}$ Mice expressing mutated human APP and mutated human tau develop severalfold increased neurofibrillary tangles, compared with mice expressing only mutated human tau. ${ }^{62}$ Neurons without tau are resistant to $A \beta$ toxicity, and APP transgenic mice lacking tau develop A $\beta$ pathology but remain cognitively normal. ${ }^{63,64}$ A combined reduction of both $A \beta$ and tau, but not $A \beta$ alone, was found to improve cognition in a mouse model with both plaques and tangles. ${ }^{65}$ Increasing evidence suggests that $A \beta$ and tau interact to either cause or enhance $\mathrm{AD} .{ }^{66} \mathrm{~A}$ therapeutic strategy targeting both pathologies is currently being sought for the effective treatment of AD. ${ }^{66}$

BACE- 1 and $\gamma$-secretase catalyze the sequential cleavage of APP to generate A $\beta .^{2}$ Likewise, Cdk5 and GSK3 $\beta$ are recognized as the major kinases that phosphorylate tau in the AD brain. ${ }^{12,14}$ Repeated failures of clinical trials targeting $\gamma$-secretase ${ }^{3}$ or GSK3 $\beta^{17-19,67}$ in mild to moderate AD patients have shifted the focus of drug development against AD to BACE-1 and Cdk5. ${ }^{1,20}$ However, although BACE-1 knockout mice do not develop plaques and knockdown of BACE-1 in the hippocampus reduces A $\beta$ in the APP mouse model, ${ }^{68,69}$ a direct pharmacological inhibition of BACE-1 impairs synaptic plasticity and cognition in mice. ${ }^{6,7} \mathrm{Cdk} 5$, on the other hand, is involved in brain development and adult hippocampal neurogenesis, and Cdk5 knockout mice die perinatally. ${ }^{15,16}$ These observations suggest that a direct pharmacological inhibition of BACE-1 or Cdk5 is associated with mechanism-based adverse effects.

Cdk5 requires the p35 subunit to become active. Egr-1 is the main inducer of p35 expression and activator of Cdk5 in the brain. ${ }^{32,43}$ Previously, we showed that Egr-1 knockout mice have reduced levels of phosphorylated tau and 
A
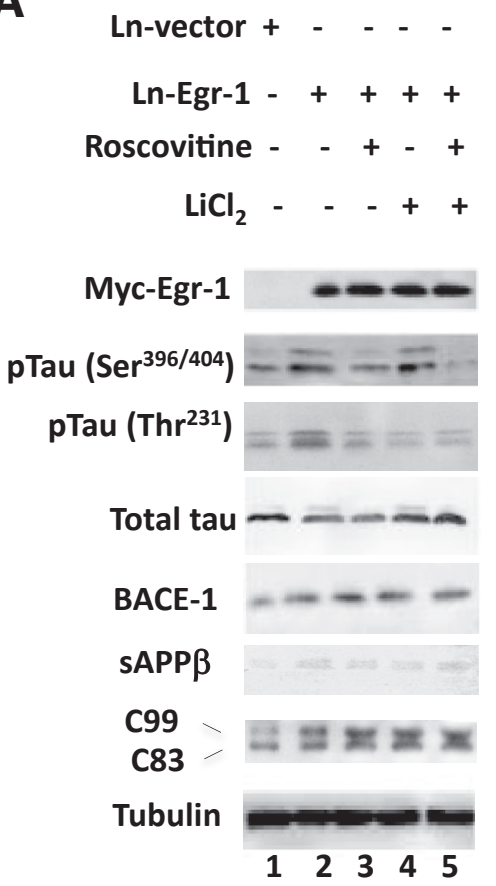

B
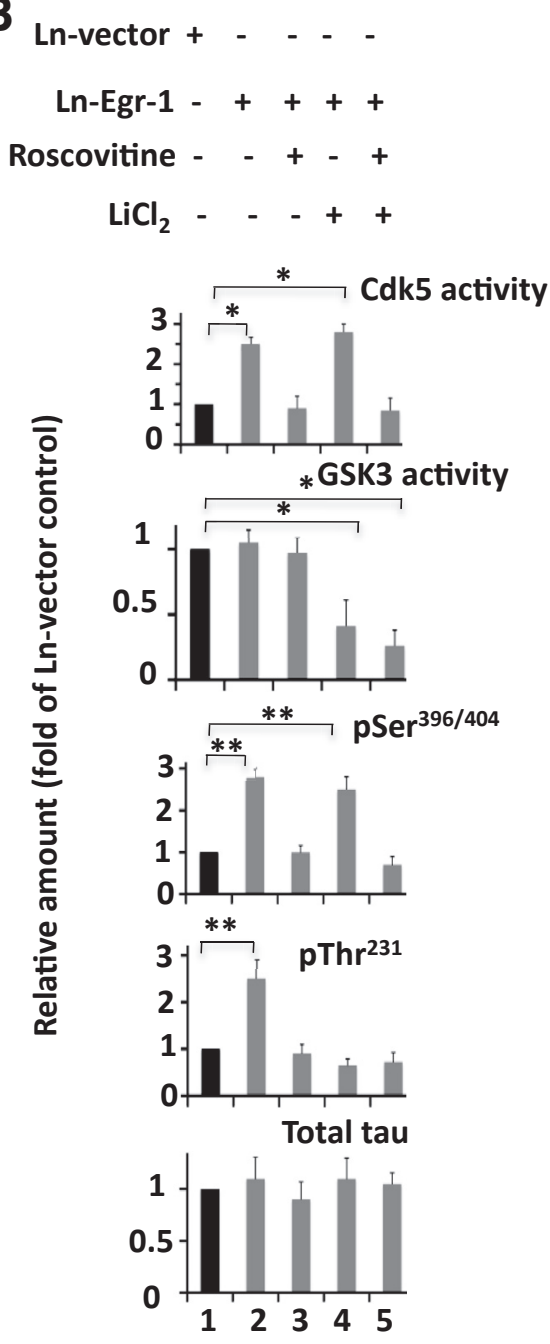

C

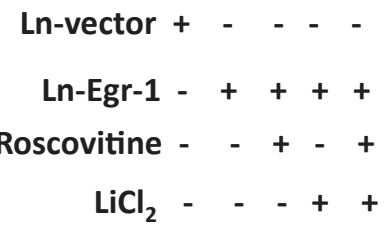

BACE-1 protein
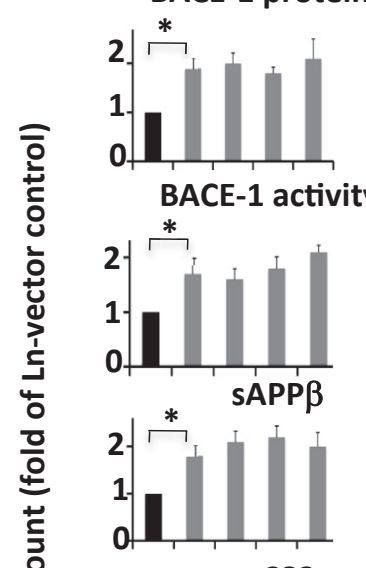

C83

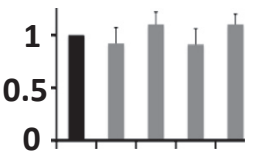

4. $\stackrel{* *}{ } \mathrm{C99}$
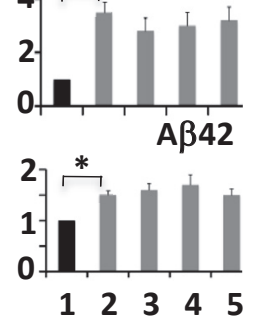

Figure 11 Egr-1 promotes amyloidogenic APP processing independent of Cdk5 and tau phosphorylation. Mouse hippocampal primary neurons infected with Ln-Egr-1 or Ln-vector were treated with $400 \mathrm{nmol} / \mathrm{L}$ roscovitine, $10 \mathrm{mmol} / \mathrm{L}$ lithium chloride $\left(\mathrm{LiCl}_{2}\right)$, or vehicle for 15 minutes and analyzed for Cdk5 and GSK3 $\beta$ activities, tau phosphorylation (Western blotting), BACE-1 protein (Western blotting), and BACE-1 activity (fluorogenic BACE-1 activity assay). Western blotting was performed for $\mathrm{C} 99$ and $\mathrm{C} 83$ using mouse anti-APP-C-terminal fragment antibody. Culture medium was analyzed for mouse SAPP $\beta$ (Western blotting) and A $\beta 42$ (enzyme-linked immunosorbent assay). A: Representative Western blots. B and C: Quantification. $n=4$ independent cultures. ${ }^{*} P<0.05$, $* * P<0.01$ (one-way analysis of variance).

overexpression of Egr-1 promotes Cdk5-mediated tau phosphorylation in neurons and in rat hippocampus. ${ }^{32}$ In this study, we showed that Egr-1 also promotes tau phosphorylation by GSK3 $\beta$ at $\mathrm{Thr}^{231}$. We also demonstrated that Egr-1, by activating BACE-1, accelerates amyloidogenic APP processing in neurons. Our studies suggest that Egr-1 is a physiological regulator of tau phosphorylation and $A \beta$ production in the brain. More important, targeted inhibition of Egr-1 in the hippocampus of cognitively deficient 3xTg$\mathrm{AD}$ mice reduces $\mathrm{A} \beta$ load and hyperphosphorylated tau, and rescues cognitive impairment (this study). Egr-1 mice are healthy and do not display any undesirable phenotype, except female infertility. ${ }^{70}$ Our data suggest that Egr-1 is a potential therapeutic candidate for treatment of $\mathrm{AD}$.
Extracellular $\mathrm{A} \beta$ promotes intracellular tau hyperphosphorylation by activating several kinases, including Cdk5. ${ }^{59,60}$ BACE- 1 is the rate-limiting enzyme in A $\beta$ generation, and its activation triggers amyloidogenic APP processing. ${ }^{2}$ This implies that BACE-1 activation will activate Cdk5 and promote both tau phosphorylation and amyloidogenic APP processing. Studies have also shown that Cdk5 activates BACE-1, leading to aberrant APP processing. ${ }^{55-57}$ These observations suggest that activation of BACE-1 alone or Cdk5 alone can promote both amyloidogenic APP processing and tau phosphorylation. Egr-1 activates both $\mathrm{Cdk} 5$ and $\mathrm{BACE}-1$ and promotes $\mathrm{A} \beta$ production and tau phosphorylation in neurons and mouse brain (this study). However, we showed that in neurons, inhibition of 

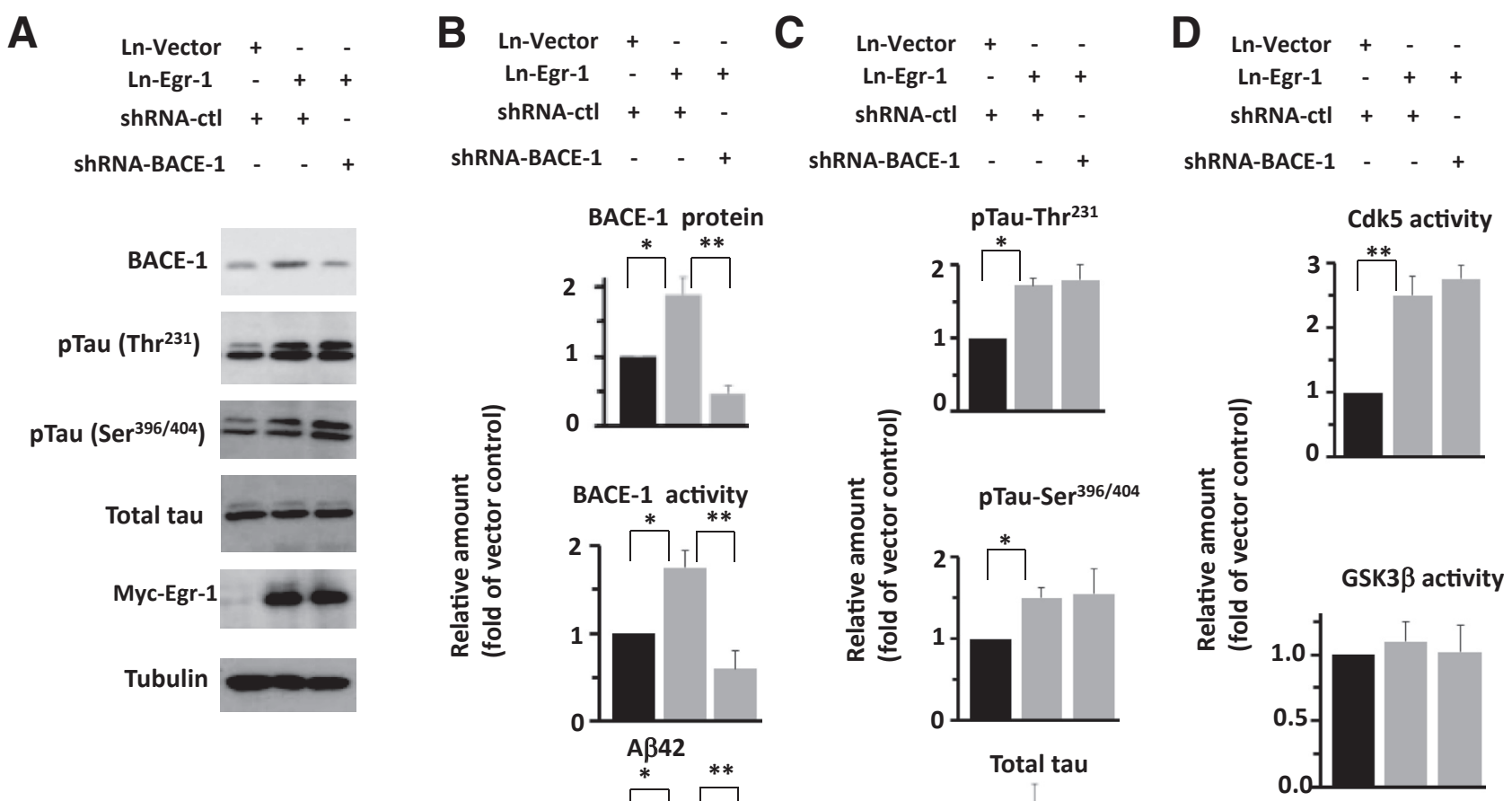

Figure 12 Egr-1 promotes tau phosphorylation independent of BACE-1 and A 3 . Mouse hippocampal primary neurons were coinfected with Ln-Egr-1 and shRNA-BACE-1 and analyzed. A: Representative Western blots. B: Quantification of BACE-1 and Aß42. C: Quantification of tau phosphorylation. D: Quantification of Cdk5 and GSK3 $\beta$ activities. Data are expressed as average \pm SEM. $n=3$ cultures. ${ }^{*} P<0.05$, ${ }^{* \star} P<0.01$ (one-way analysis of variance).

Cdk5 blocks Egr-1-induced tau phosphorylation without affecting BACE-1 activation and A $\beta$ generation (Figure 11). Likewise, BACE-1 inhibition blocks Egr-1-induced A $\beta$ production but has no influence on Cdk5 activity and tau phosphorylation (Figure 12). Our data indicate that in neurons, Egr-1 promotes tau phosphorylation and $\mathrm{A} \beta$ production, activating, respectively, Cdk5 and BACE-1. However, in a previous study, removal of extracellular $A \beta$ was shown to clear tau pathology in the brains of $3 \mathrm{xTg}-\mathrm{AD}$ mice, indicating that tau pathology is downstream of $A \beta$ in these mice. ${ }^{65}$ The reduction in the level of phosphorylated tau in the hippocampus of $3 x \mathrm{Tg}-\mathrm{AD}$ mice receiving shRNA-Egr-1 may be because of the inhibition of both Cdk5 and BACE-1 activities.

Among all tau sites tested, $\mathrm{Thr}^{231}$ is most phosphorylated in the hippocampus of 3xTg-AD mice (Figure 4A). Previous studies have shown that tau is phosphorylated at $\mathrm{Thr}^{231}$ in AD but not in the normal brain, ${ }^{71,72}$ and phosphorylation at this site significantly inhibits ability of tau to bind and stabilize microtubules. ${ }^{50}$ In addition, phosphorylation at $\mathrm{Thr}^{231}$ causes a conformational change that exposes the C-terminal region of tau for further phosphorylation. ${ }^{47}$ Furthermore, prolyl isomerase 1 specifically binds to phosphorylated $\mathrm{Thr}^{231}$ of tau and facilitates the cis-trans configuration change of the pThr-Pro bond, thereby enabling PP2A to dephosphorylate tau and to restore tau function to bind to microtubules. ${ }^{73}$ Accumulation of $\mathrm{Thr}^{231}$ phosphorylated tau in the $\mathrm{AD}$ brain was suggested to sequester prolyl isomerase 1 and cause depletion of soluble prolyl isomerase $1 .^{73}$ Tau phosphorylation at $\mathrm{Thr}^{231}$ is implicated to play an important role in the development of tau dysfunction associated with AD.

GSK3 $\beta$ preferentially phosphorylates tau $\mathrm{Thr}^{231}$ in the brain. ${ }^{47,49,50}$ In this study, we find that inhibition of Egr-1 by shRNA reduces tau phosphorylation at $\mathrm{Thr}^{231}$. However, Egr-1 does not activate GSK3 $\beta$ (Figure 6). ${ }^{32}$ It is, therefore, likely that Egr-1 regulates tau phosphorylation by GSK3 $\beta$ at $\mathrm{Thr}^{231}$ indirectly. Some of GSK3 $\beta$ substrates are first phosphorylated (primed) by another kinase at position $\mathrm{n}+4$ to generate a sequence $\mathrm{S} / \mathrm{T} \mathrm{XXXpS/T}$ motif, recognized by GSK3 $\beta .^{49,50}$ Previous studies have shown that Cdk5 phosphorylates tau at $\operatorname{Ser}^{235}$ and primes tau for phosphorylation at $\mathrm{Thr}^{213}$ by GSK3 $\beta .^{48,49}$ In this study, we showed that in rat hippocampal primary neurons in culture, overexpression of Egr-1 promotes tau phosphorylation at both $\mathrm{Ser}^{235}$ and $\mathrm{Thr}^{231}$. Although the phosphorylation at $\mathrm{Ser}^{235}$ is Cdk5 dependent, phosphorylation at $\mathrm{Thr}^{231}$ requires activity of both Cdk5 and GSK3 $\beta$. More important, 
blocking $\operatorname{Ser}^{235}$ phosphorylation by inhibition of Cdk5 blocks phosphorylation at $\mathrm{Thr}^{231}$. Previous reports ${ }^{47,49}$ and these data together suggest that Egr-1 activates Cdk5, which phosphorylates tau at $\mathrm{Ser}^{235}$ and primes tau for $\mathrm{Thr}^{231}$ phosphorylation by GSK $3 \beta$. GSK $3 \beta$ subsequently phosphorylates tau at $\mathrm{Thr}^{231}$.

$3 \times \mathrm{Tg}-\mathrm{AD}$ mice, in addition to human tau, also express endogenous murine tau. A previous study showed that in 3xTg-AD mice, endogenous tau is phosphorylated at $\mathrm{Ser}^{396 / 404}$ and $\mathrm{Thr}^{181}$, and the authors suggested that these phosphorylations trigger phosphorylation and aggregation of human tau. ${ }^{74}$ In the current study, we found that silencing Egr1 reduces tau phosphorylation at several sites, including $\mathrm{Ser}^{404}$ and $\mathrm{Thr}^{181}$ in both 3xTg-AD and nTg mice (Figure 4). A previous study ${ }^{74}$ and our data together suggest that Egr-1 knockdown may have reduced some phosphorylation of human tau in 3xTg-AD mice by inhibiting phosphorylation of endogenous tau at $\mathrm{Ser}^{404}$ and $\mathrm{Thr}^{181}$. Phosphorylation of endogenous tau does not affect cognition of 3xTg-AD mice. ${ }^{74}$ Improvements in the learning and memory of $3 \times \mathrm{Tg}-\mathrm{AD}$ mice because of knockdown of Egr-1 in the hippocampus may have occurred independent of endogenous tau phosphorylation and endogenous tau-induced phosphorylation of human tau.

Knockdown of Egr-1 reduces tau phosphorylation at several sites, including $\mathrm{Ser}^{262}$, in both $3 \mathrm{xTg}$-AD and $\mathrm{nTg}$ mice. $\mathrm{Ser}^{262}$ is a non-proline-directed site and is not phosphorylated by $\mathrm{Cdk} 5 .^{46}$ Previously, we showed that Cdk5 phosphorylates and inactivates PP1, which dephosphorylates Ser ${ }^{262}$ phosphorylated tau. ${ }^{46}$ Thus, Cdk5, by phosphorylating and inhibiting PP1 activity, reduces tau phosphorylation at $\mathrm{Ser}^{262}$. Both nTg and 3xTg-AD mice receiving shRNA-Egr-1 display reduced phosphorylated PP1 when compared to those receiving shRNA-Ctl (Figure 5). These data indicate that silencing Egr-1 activates PP1. It is, therefore, possible that in mice, silencing Egr-1 reduces tau phosphorylation at $\operatorname{Ser}^{262}$ via PP1 activation.

The hypothesis that vascular disorders may play a role in $\mathrm{AD}$ was criticized on the basis of neuropathological evidence supporting an additive effect of cerebral infarction on neurodegenerative lesions. ${ }^{75}$ In addition, stroke or transient ischemic attacks are exclusion criteria for an $\mathrm{AD}$ diagnosis. ${ }^{76}$ However, epidemiological studies have indicated that $\mathrm{AD}$ and vascular dementia share common risk factors. ${ }^{20,21}$ In addition, in most cases of dementia, vascular lesions and degenerative processes of $\mathrm{AD}$ coexist. ${ }^{77}$ Hypoxic ischemia is a powerful promoter of cerebral amyloidogenesis and tau hyperphosphorylation in humans, rats, and mice. ${ }^{23,24}$ Increasing evidence suggests that there is a molecular link between AD and vascular dementia. ${ }^{20,21}$

In the brain, Egr-1 is induced by injury, transient focal ischemia, and hypoxia, and plays a key role in the induction of both cardiovascular and cerebrovascular pathologies. ${ }^{27,28}$ BACE-1 expression is also increased during transient ischemia, hypoxia, inflammation, and head trauma. ${ }^{20}$ Likewise, Cdk5 is activated during hypoxia and ischemic stroke in the brain. ${ }^{78,79}$ It is plausible that vascular insults induce
Egr-1, which activates BACE-1 and Cdk5 and promotes amyloidogenesis and tau hyperphosphorylation observed in cerebrovascular pathologies.

\section{Acknowledgments}

We thank Heather Pekeles for editing the manuscript and Dr. Hyman Schipper (Lady Davis Institute for Medical Research) for providing the $3 \times \mathrm{Tg}-\mathrm{AD}$ and nontransgenic mice.

H.K.P. conceived the project, designed the experiments, supervised the study, analyzed the data, and wrote the manuscript; X.Q. designed and performed most of the experiments and assisted in data analysis; Y.W. designed and validated the shRNA-Egr-1 construct and prepared lentivirus.

\section{References}

1. Giacobini E, Gold G: Alzheimer disease therapy: moving from amyloid-beta to tau. Nat Rev Neurol 2013, 9:677-686

2. Vassar R, Kovacs DM, Yan R, Wong PC: The beta-secretase enzyme BACE in health and Alzheimer's disease: regulation, cell biology, function, and therapeutic potential. J Neurosci 2009, 29: 12787-12794

3. Hardy J, Bogdanovic N, Winblad B, Portelius E, Andreasen N, Cedazo-Minguez A, Zetterberg H: Pathways to Alzheimer's disease. J Intern Med 2014, 275:296-303

4. Shimizu H, Tosaki A, Kaneko K, Hisano T, Sakurai T, Nukina N: Crystal structure of an active form of BACE1, an enzyme responsible for amyloid beta protein production. Mol Cell Biol 2008, 28: 3663-3671

5. Vassar R: BACE1 inhibitor drugs in clinical trials for Alzheimer's disease. Alzheimers Res Ther 2014, 6:89

6. Filser S, Ovsepian SV, Masana M, Blazquez-Llorca L, Brandt Elvang A, Volbracht C, Muller MB, Jung CK, Herms J: Pharmacological inhibition of BACE1 impairs synaptic plasticity and cognitive functions. Biol Psychiatry 2015, 77:729-739

7. Barao S, Moechars D, Lichtenthaler SF, De Strooper B: BACE1 physiological functions may limit its use as therapeutic target for Alzheimer's disease. Trends Neurosci 2016, 39:158-169

8. Wong PC, Zheng H, Chen H, Becher MW, Sirinathsinghji DJ, Trumbauer ME, Chen HY, Price DL, Van der Ploeg LH, Sisodia SS: Presenilin 1 is required for Notch1 and DII1 expression in the paraxial mesoderm. Nature 1997, 387:288-292

9. Donoviel DB, Hadjantonakis AK, Ikeda M, Zheng H, Hyslop PS, Bernstein A: Mice lacking both presenilin genes exhibit early embryonic patterning defects. Genes Dev 1999, 13:2801-2810

10. Xia W, Wong ST, Hanlon E, Morin P: gamma-Secretase modulator in Alzheimer's disease: shifting the end. J Alzheimers Dis 2012, 31: 685-696

11. Green RC, Schneider LS, Amato DA, Beelen AP, Wilcock G, Swabb EA, Zavitz KH: Effect of tarenflurbil on cognitive decline and activities of daily living in patients with mild Alzheimer disease: a randomized controlled trial. JAMA 2009, 302:2557-2564

12. Brunden KR, Trojanowski JQ, Lee VM: Advances in tau-focused drug discovery for Alzheimer's disease and related tauopathies. Nat Rev Drug Discov 2009, 8:783-793

13. Grundke-Iqbal I, Iqbal K, Tung YC, Quinlan M, Wisniewski HM, Binder LI: Abnormal phosphorylation of the microtubule-associated protein tau (tau) in Alzheimer cytoskeletal pathology. Proc Natl Acad Sci U S A 1986, 83:4913-4917 
14. Hanger DP, Anderton BH, Noble W: Tau phosphorylation: the therapeutic challenge for neurodegenerative disease. Trends Mol Med 2009, 15:112-119

15. Hellmich MR, Pant HC, Wada E, Battey JF: Neuronal cdc2-like kinase: a cdc2-related protein kinase with predominantly neuronal expression. Proc Natl Acad Sci U S A 1992, 89:10867-10871

16. Lagace DC, Benavides DR, Kansy JW, Mapelli M, Greengard P, Bibb JA, Eisch AJ: Cdk5 is essential for adult hippocampal neurogenesis. Proc Natl Acad Sci U S A 2008, 105:18567-18571

17. Macdonald A, Briggs K, Poppe M, Higgins A, Velayudhan L, Lovestone S: A feasibility and tolerability study of lithium in Alzheimer's disease. Int J Geriatr Psychiatry 2008, 23:704-711

18. del Ser T, Steinwachs KC, Gertz HJ, Andres MV, Gomez-Carrillo B, Medina M, Vericat JA, Redondo P, Fleet D, Leon T: Treatment of Alzheimer's disease with the GSK-3 inhibitor tideglusib: a pilot study. J Alzheimers Dis 2013, 33:205-215

19. Tolosa E, Litvan I, Hoglinger GU, Burn D, Lees A, Andres MV, Gomez-Carrillo B, Leon T, Del Ser T; TAUROS Investigators: A phase 2 trial of the GSK-3 inhibitor tideglusib in progressive supranuclear palsy. Mov Disord 2014, 29:470-478

20. Cole SL, Vassar R: Linking vascular disorders and Alzheimer's disease: potential involvement of BACE1. Neurobiol Aging 2009, 30: $1535-1544$

21. van Norden AG, van Dijk EJ, de Laat KF, Scheltens P, Olderikkert MG, de Leeuw FE: Dementia: Alzheimer pathology and vascular factors: from mutually exclusive to interaction. Biochim Biophys Acta 2012, 1822:340-349

22. Sparks DL, Hunsaker JC 3rd, Scheff SW, Kryscio RJ, Henson JL, Markesbery WR: Cortical senile plaques in coronary artery disease, aging and Alzheimer's disease. Neurobiol Aging 1990, 11: 601-607

23. Wen Y, Onyewuchi O, Yang S, Liu R, Simpkins JW: Increased betasecretase activity and expression in rats following transient cerebral ischemia. Brain Res 2004, 1009:1-8

24. Wen Y, Yang S, Liu R, Brun-Zinkernagel AM, Koulen P, Simpkins JW: Transient cerebral ischemia induces aberrant neuronal cell cycle re-entry and Alzheimer's disease-like tauopathy in female rats. J Biol Chem 2004, 279:22684-22692

25. Sparks DL, Scheff SW, Liu H, Landers TM, Coyne CM, Hunsaker JC 3rd: Increased incidence of neurofibrillary tangles (NFT) in non-demented individuals with hypertension. J Neurol Sci 1995, 131:162-169

26. Beckmann AM, Wilce PA: Egr transcription factors in the nervous system. Neurochem Int 1997, 31:477-510; discussion 517-526

27. Yan SF, Fujita T, Lu J, Okada K, Shan Zou Y, Mackman N, Pinsky DJ, Stern DM: Egr-1, a master switch coordinating upregulation of divergent gene families underlying ischemic stress. Nat Med 2000, 6:1355-1361

28. Khachigian LM: Early growth response-1 in cardiovascular pathobiology. Circ Res 2006, 98:186-191

29. Khachigian LM, Lindner V, Williams AJ, Collins T: Egr-1-induced endothelial gene expression: a common theme in vascular injury. Science 1996, 271:1427-1431

30. Gomez Ravetti M, Rosso OA, Berretta R, Moscato P: Uncovering molecular biomarkers that correlate cognitive decline with the changes of hippocampus' gene expression profiles in Alzheimer's disease. PLoS One 2010, 5:e10153

31. Killick R, Ribe EM, Al-Shawi R, Malik B, Hooper C, Fernandes C, Dobson R, Nolan PM, Lourdusamy A, Furney S, Lin K, Breen G, Wroe R, To AW, Leroy K, Causevic M, Usardi A, Robinson M, Noble W, Williamson R, Lunnon K, Kellie S, Reynolds $\mathrm{CH}$, Bazenet C, Hodges A, Brion JP, Stephenson J, Paul Simons J, Lovestone S: Clusterin regulates beta-amyloid toxicity via Dickkopf1-driven induction of the wnt-PCP-JNK pathway. Mol Psychiatry 2014, 19:88-98

32. Lu Y, Li T, Qureshi HY, Han D, Paudel HK: Early growth response 1 (Egr-1) regulates phosphorylation of microtubule- associated protein tau in mammalian brain. J Biol Chem 2011 , 286:20569-20581

33. Hendrickx A, Pierrot N, Tasiaux B, Schakman O, Brion JP, KienlenCampard P, De Smet C, Octave JN: Epigenetic induction of EGR-1 expression by the amyloid precursor protein during exposure to novelty. PLoS One 2013, 8:e74305

34. MacGibbon GA, Lawlor PA, Walton M, Sirimanne E, Faull RL, Synek B, Mee E, Connor B, Dragunow M: Expression of Fos, Jun, and Krox family proteins in Alzheimer's disease. Exp Neurol 1997, $147: 316-332$

35. Bakalash S, Pham M, Koronyo Y, Salumbides BC, Kramerov A, Seidenberg H, Berel D, Black KL, Koronyo-Hamaoui M: Egr1 expression is induced following glatiramer acetate immunotherapy in rodent models of glaucoma and Alzheimer's disease. Invest Ophthalmol Vis Sci 2011, 52:9033-9046

36. Gatta V, D’Aurora M, Granzotto A, Stuppia L, Sensi SL: Early and sustained altered expression of aging-related genes in young $3 \times \mathrm{Tg}$ AD mice. Cell Death Dis 2014, 5:e1054

37. Oddo S, Caccamo A, Shepherd JD, Murphy MP, Golde TE, Kayed R, Metherate R, Mattson MP, Akbari Y, LaFerla FM: Triple-transgenic model of Alzheimer's disease with plaques and tangles: intracellular Abeta and synaptic dysfunction. Neuron 2003, 39:409-421

38. Qureshi HY, Han D, MacDonald R, Paudel HK: Overexpression of 14-3-3z promotes tau phosphorylation at Ser262 and accelerates proteosomal degradation of synaptophysin in rat primary hippocampal neurons. PLoS One 2013, 8:e84615

39. Qin X, Jiang Y, Tse YC, Wang Y, Wong TP, Paudel HK: Early growth response 1 (Egr-1) regulates N-methyl-d-aspartate receptor (NMDAR)-dependent transcription of PSD-95 and alpha-amino-3hydroxy-5-methyl-4-isoxazole propionic acid receptor (AMPAR) trafficking in hippocampal primary neurons. J Biol Chem 2015, 290: 29603-29616

40. Vorhees CV, Williams MT: Morris water maze: procedures for assessing spatial and related forms of learning and memory. Nat Protoc 2006, 1:848-858

41. Laird FM, Cai H, Savonenko AV, Farah MH, He K, Melnikova T, Wen H, Chiang HC, Xu G, Koliatsos VE, Borchelt DR, Price DL, Lee HK, Wong PC: BACE1, a major determinant of selective vulnerability of the brain to amyloid-beta amyloidogenesis, is essential for cognitive, emotional, and synaptic functions. J Neurosci 2005, 25:11693-11709

42. Qin X, Wang Y, Paudel HK: Early growth response 1 (Egr-1) is a transcriptional activator of beta-secretase 1 (BACE-1) in the brain J Biol Chem 2016, 291:22276-22287

43. Harada T, Morooka T, Ogawa S, Nishida E: ERK induces p35, a neuron-specific activator of Cdk5, through induction of Egr1. Nat Cell Biol 2001, 3:453-459

44. Jicha GA, Weaver C, Lane E, Vianna C, Kress Y, Rockwood J, Davies P: cAMP-dependent protein kinase phosphorylations on tau in Alzheimer's disease. J Neurosci 1999, 19:7486-7494

45. Patrick GN, Zukerberg L, Nikolic M, de la Monte S, Dikkes P, Tsai LH: Conversion of p35 to p25 deregulates Cdk5 activity and promotes neurodegeneration. Nature 1999, 402:615-622

46. Li T, Chalifour LE, Paudel HK: Phosphorylation of protein phosphatase 1 by cyclin-dependent protein kinase 5 during nerve growth factor-induced PC12 cell differentiation. J Biol Chem 2007, 282: 6619-6628

47. Lin YT, Cheng JT, Liang LC, Ko CY, Lo YK, Lu PJ: The binding and phosphorylation of Thr231 is critical for Tau's hyperphosphorylation and functional regulation by glycogen synthase kinase 3beta. J Neurochem 2007, 103:802-813

48. Sengupta A, Novak M, Grundke-Iqbal I, Iqbal K: Regulation of phosphorylation of tau by cyclin-dependent kinase 5 and glycogen synthase kinase-3 at substrate level. FEBS Lett 2006, 580: 5925-5933

49. Li T, Hawkes C, Qureshi HY, Kar S, Paudel HK: Cyclin-dependent protein kinase 5 primes microtubule-associated protein tau 
site-specifically for glycogen synthase kinase 3beta. Biochemistry 2006, 45:3134-3145

50. Cho JH, Johnson GV: Primed phosphorylation of tau at Thr231 by glycogen synthase kinase 3beta (GSK3beta) plays a critical role in regulating tau's ability to bind and stabilize microtubules. J Neurochem 2004, 88:349-358

51. Mukherjee A, Hersh LB: Regulation of amyloid beta-peptide levels by enzymatic degradation. J Alzheimers Dis 2002, 4:341-348

52. Iwata N, Tsubuki S, Takaki Y, Shirotani K, Lu B, Gerard NP, Gerard C, Hama E, Lee HJ, Saido TC: Metabolic regulation of brain Abeta by neprilysin. Science 2001, 292:1550-1552

53. Miller BC, Eckman EA, Sambamurti K, Dobbs N, Chow KM, Eckman CB, Hersh LB, Thiele DL: Amyloid-beta peptide levels in brain are inversely correlated with insulysin activity levels in vivo. Proc Natl Acad Sci U S A 2003, 100:6221-6226

54. Sisodia SS, St George-Hyslop PH: gamma-Secretase, Notch, Abeta and Alzheimer's disease: where do the presenilins fit in? Nat Rev Neurosci 2002, 3:281-290

55. Wen Y, Yu WH, Maloney B, Bailey J, Ma J, Marie I, Maurin T, Wang L, Figueroa H, Herman M, Krishnamurthy P, Liu L, Planel E, Lau LF, Lahiri DK, Duff K: Transcriptional regulation of betasecretase by $\mathrm{p} 25 / \mathrm{cdk} 5$ leads to enhanced amyloidogenic processing. Neuron 2008, 57:680-690

56. Song WJ, Son MY, Lee HW, Seo H, Kim JH, Chung SH: Enhancement of BACE1 activity by p25/Cdk5-mediated phosphorylation in Alzheimer's disease. PLoS One 2015, 10:e0136950

57. Sadleir KR, Vassar R: Cdk5 protein inhibition and Abeta42 increase BACE1 protein level in primary neurons by a post-transcriptional mechanism: implications of CDK5 as a therapeutic target for Alzheimer disease. J Biol Chem 2012, 287:7224-7235

58. Ly PT, Wu Y, Zou H, Wang R, Zhou W, Kinoshita A, Zhang M, Yang Y, Cai F, Woodgett J, Song W: Inhibition of GSK3betamediated BACE1 expression reduces Alzheimer-associated phenotypes. J Clin Invest 2013, 123:224-235

59. Karran E, Mercken M, De Strooper B: The amyloid cascade hypothesis for Alzheimer's disease: an appraisal for the development of therapeutics. Nat Rev Drug Discov 2011, 10:698-712

60. Qu J, Nakamura T, Cao G, Holland EA, McKercher SR, Lipton SA: S-nitrosylation activates Cdk5 and contributes to synaptic spine loss induced by beta-amyloid peptide. Proc Natl Acad Sci U S A 2011, 108:14330-14335

61. Gotz J, Chen F, van Dorpe J, Nitsch RM: Formation of neurofibrillary tangles in P3011 tau transgenic mice induced by Abeta 42 fibrils. Science 2001, 293:1491-1495

62. Lewis J, Dickson DW, Lin WL, Chisholm L, Corral A, Jones G, Yen SH, Sahara N, Skipper L, Yager D, Eckman C, Hardy J, Hutton M, McGowan E: Enhanced neurofibrillary degeneration in transgenic mice expressing mutant tau and APP. Science 2001, 293: $1487-1491$

63. Roberson ED, Scearce-Levie K, Palop JJ, Yan F, Cheng IH, Wu T, Gerstein H, Yu GQ, Mucke L: Reducing endogenous tau ameliorates amyloid beta-induced deficits in an Alzheimer's disease mouse model. Science 2007, 316:750-754

64. Rapoport M, Dawson HN, Binder LI, Vitek MP, Ferreira A: Tau is essential to beta-amyloid-induced neurotoxicity. Proc Natl Acad Sci U S A 2002, 99:6364-6369
65. Oddo S, Billings L, Kesslak JP, Cribbs DH, LaFerla FM: Abeta immunotherapy leads to clearance of early, but not late, hyperphosphorylated tau aggregates via the proteasome. Neuron 2004, 43 : 321-332

66. Ittner LM, Gotz J: Amyloid-beta and tau: a toxic pas de deux in Alzheimer's disease. Nat Rev Neurosci 2011, 12:65-72

67. Yoshiyama Y, Lee VM, Trojanowski JQ: Therapeutic strategies for tau mediated neurodegeneration. J Neurol Neurosurg Psychiatry 2013, 84:784-795

68. Luo Y, Bolon B, Kahn S, Bennett BD, Babu-Khan S, Denis P, Fan W, Kha H, Zhang J, Gong Y, Martin L, Louis JC, Yan Q, Richards WG, Citron M, Vassar R: Mice deficient in BACE1, the Alzheimer's beta-secretase, have normal phenotype and abolished beta-amyloid generation. Nat Neurosci 2001, 4:231-232

69. Singer O, Marr RA, Rockenstein E, Crews L, Coufal NG, Gage FH, Verma IM, Masliah E: Targeting BACE1 with siRNAs ameliorates Alzheimer disease neuropathology in a transgenic model. Nat Neurosci 2005, 8:1343-1349

70. Lee SL, Sadovsky Y, Swirnoff AH, Polish JA, Goda P, Gavrilina G, Milbrandt J: Luteinizing hormone deficiency and female infertility in mice lacking the transcription factor NGFI-A (Egr-1). Science 1996, 273:1219-1221

71. Singer D, Lehmann J, Hanisch K, Hartig W, Hoffmann R: Neighbored phosphorylation sites as PHF-tau specific markers in Alzheimer's disease. Biochem Biophys Res Commun 2006, 346: 819-828

72. Hoffmann R, Lee VM, Leight S, Varga I, Otvos L Jr: Unique Alzheimer's disease paired helical filament specific epitopes involve double phosphorylation at specific sites. Biochemistry 1997, 36: $8114-8124$

73. Lu PJ, Wulf G, Zhou XZ, Davies P, Lu KP: The prolyl isomerase Pin1 restores the function of Alzheimer-associated phosphorylated tau protein. Nature 1999, 399:784-788

74. Baglietto-Vargas D, Kitazawa M, Le EJ, Estrada-Hernandez T, Rodriguez-Ortiz CJ, Medeiros R, Green KN, LaFerla FM: Endogenous murine tau promotes neurofibrillary tangles in $3 \times \mathrm{Tg}-$ AD mice without affecting cognition. Neurobiol Dis 2014, 62: 407-415

75. Schneider JA, Wilson RS, Bienias JL, Evans DA, Bennett DA: Cerebral infarctions and the likelihood of dementia from Alzheimer disease pathology. Neurology 2004, 62:1148-1155

76. Dubois B, Feldman HH, Jacova C, Dekosky ST, Barberger-Gateau P, Cummings J, Delacourte A, Galasko D, Gauthier S, Jicha G, Meguro K, O'Brien J, Pasquier F, Robert P, Rossor M, Salloway S, Stern Y, Visser PJ, Scheltens P: Research criteria for the diagnosis of Alzheimer's disease: revising the NINCDS-ADRDA criteria. Lancet Neurol 2007, 6:734-746

77. Bowler JV: Acetylcholinesterase inhibitors for vascular dementia and Alzheimer's disease combined with cerebrovascular disease. Stroke 2003, 34:584-586

78. Slevin M, Krupinski J: Cyclin-dependent kinase-5 targeting for ischaemic stroke. Curr Opin Pharmacol 2009, 9:119-124

79. Wen Y, Yang SH, Liu R, Perez EJ, Brun-Zinkernagel AM, Koulen P, Simpkins JW: Cdk5 is involved in NFT-like tauopathy induced by transient cerebral ischemia in female rats. Biochim Biophys Acta 2007, 1772:473-483 